\title{
SSL1, a suppressor of a HIS4 5'-UTR stem-loop mutation, is essential for translation initiation and affects UV resistance in yeast
}

\author{
Heejeong Yoon, Stephen P. Miller, Edward K. Pabich, and Thomas F. Donahue \\ Department of Biology, Indiana University, Bloomington, Indiana 47405 USA
}

The SSL1 locus was identified as a trans-acting suppressor that restores HIS4 expression despite a stem-loop structure in the 5'-UTR. SSL1 encodes an essential protein of $52 \mathrm{kD}$ with features characteristic of a protein with multiple zinc fingers. The mechanism of SSL1 suppression is not related to altering his 4 transcription or removing the stem-loop sequence from the $5^{\prime}$-UTR; rather, 3- to 5 -fold increases in His 4 translational expression are observed indicating a post-transcriptional mechanism for SSL1 suppression. SSL1 suppressor mutants that are conditional for growth have altered polysome profiles at the restrictive temperature, and their cell-free extracts are thermolabile in their ability to translate exogenously added mRNA. In addition, the mechanism of suppression appears to be specific for stem-loop structures placed near the $5^{\prime}$ end of the message as opposed to a stem-loop located at a downstream position in the $5^{\prime}$-UTR. These observations suggest a role for this protein in promoting translation initiation presumably at the level of ribosomal binding to mRNA. Surprisingly, SSL1 suppressor mutations that are shown to confer an in vivo and in vitro defect in translation initiation also rendered yeast hypersensitive to UV irradiation. This latter phenotype was observed previously with a mutation in the SSL2 suppressor gene, which encodes the yeast homolog of the human gene $E R C C-3$, for which a defective form causes xeroderma pigmentosum. In light of the related effects of mutations in the SSL1 and SSL2 genes, the encoded proteins may functionally interact both to promote DNA repair and perform an essential function during translation initiation.

[Key Words: Translation initiation; DNA repair; Stem-loop; Saccharomyces cerevisiae; SSL1 gene]

Received August 27, 1992; revised version accepted October 26, 1992.

A ribosomal scanning model has been proposed to account for molecular events between the preinitiation complex and mRNA that lead to initiation of protein synthesis in higher eukaryotes (Kozak 1991a). The basic features of this model are that the $40 \mathrm{~S}$ ribosomal subunit, in association with initiation factors and tRNA $\mathrm{Ret}_{\mathrm{i}}^{\text {, }}$ binds near or at the $5^{\prime}$ end of a mRNA and migrates in a $3^{\prime}$ direction in search of the first AUG initiator codon. Although this model is based on sound experimental evidence, it remains unclear which initiation factors might facilitate the direct binding of the ribosome to mRNA or confer the ability of the preinitiation complex to scan the mRNA. One of the best candidates for promoting ribosomal binding/scanning of mRNA is the eukaryotic initiation factor eIF-4F (Hershey 1991). This complex is composed of three subunits: eIF-4E, the 7-methyl-G, capbinding protein; eIF-4A, the prototype DEAD box RNA helicase; and p220, a subunit of unknown function. On the basis of the biochemical characterization of this factor and the associated subunits, a model has been put forth to explain at least one of the initial events in translation initiation (Sonenberg 1988; Thach 1992). In this model, eIF-4E binds the cap structure of mRNA, which brings eIF-4A, the helicase subunit of eIF-4F, to the mRNA. eIF-4A, in conjunction with another translation initiation factor, eIF-4B, is then proposed to unwind mRNA, removing secondary structure to provide a single-stranded region on the mRNA for the ribosome to bind. Although eIF-4E and eIF-4A are no doubt essential for translation initiation, a fundamental question in translation initiation is whether these factors function in vivo in the mechanistic aspects suggested by this model. Also, what other known, or as yet unidentified, factors might be involved in promoting ribosomal binding/scanning of mRNA, let alone the mechanistic details.

Recently, we have reported an alternative approach to attempt to identify the components of the translation initiation complex that might participate in ribosomal binding/scanning of mRNA (Gulyas and Donahue 1992). The strategy of this approach is to block ribosomal binding/scanning of mRNA by placing a stem-loop structure mutation in the $5^{\prime}$ untranslated region (5'-UTR) of the HIS4 gene of yeast and select genetically for suppressor mutations that overcome the block in translation initiation. Suppressor mutations that are unlinked to HIS4 
would therefore be prime candidates for identifying genes that encode factors now possessing altered specificities for the initiation process and overcome the inhibitory effect of the secondary structure in the HIS4 leader. This selection scheme resulted in the identification of four suppressor genes, SSL1-SSL4, which restore a His $4^{+}$phenotype when mutated. Characterization of the $S S L 2$ gene has shown that it encodes an essential gene product with motifs characteristic of RNA helicase/nucleic acid-binding proteins (Gulyas and Donahue 1992). SSL2 does not restore expression at HIS4 by removing the stem-loop sequence from either the DNA or the HIS4 message. Instead, the characterization of SSL2 suppression is consistent with a post-transcriptional mechanism of suppression and suggests that a helicase protein other than eIF-4A may be important during the early events of translation initiation. Interestingly, the SSL2 gene is the yeast homolog of the human gene ERCC-3 (Gulyas and Donahue 1992). A defective form of the ERCC-3 gene has been identified in a patient with xeroderma pigmentosum and clinical symptoms of Cockayne's syndrome (Weeda et al. 1990). An SSL2 allele made to resemble this defective form of ERCC-3 confers a UV-sensitive defect to yeast cells when present as the sole genomic copy of $S S L 2$. In contrast, an SSL2 suppressor mutation did not confer UV sensitivity to yeast. This suggested that SSL2 and ERCC-3 might have dual functions: a nonessential function related to DNA repair, as suggested by the repair defects observed in mutated forms of these genes, and a second essential function that is related to translation initiation. Alternatively, $S S L 2$ and, by extrapolation, ERCC-3, might have a single function in gene expression, which leads to an alteration of the expression of DNA repair genes.

Here, we report the characterization of the SSL1 suppressor gene. SSL1 encodes an essential protein with multiple Cys- $X_{2}$-Cys sequences located in its carboxyl end, suggestive of a protein that functions in nucleic acid binding. SSL1 suppressor mutants restore His 4 expression by a post-transcriptional mechanism that appears to have specificity for the position and sequence of the stem-loop in the 5'-UTR. Polysome analysis and cellfree in vitro translation assays of conditional SSL1 strains indicate that Ssll is essential for yeast translation. Taken together, these data implicate Ssll as a novel translation factor that is required for an early event during the translation initiation process in yeast. Interestingly, SSL1 suppressor strains also confer a UV sensitive phenotype to yeast. In light of other observations that we have made, these data appear to indicate that SSL1 and SSL2 gene products functionally interact to promote DNA repair and/or translation initiation.

\section{Results}

\section{Characterization of the wild-type SSL1 gene}

The SSL1 suppressor genes were identified as spontaneous $\mathrm{His}^{+}$revertants of His4- yeast strains that contained the his4-316 allele (S.P. Miller and T.F. Donahue, unpubl.). The his4-316 allele contains a 36-bp insertion sequence with perfect dyad symmetry in the DNA region that corresponds to the HIS4 5'-UTR. Upon transcription of his4-316, a stem-loop structure is predicted to reside 10 nucleotides downstream from the HIS4 transcriptional start position and 50 nucleotides upstream from the HIS4 AUG start codon. Six revertants were characterized genetically to contain $S S L 1$ suppressor mutations: JJ636 (SSL1-1), JJ637 (SSL1-2), JJ638 (SSL1-3), JJ576 (SSL1-4), JJ578 (SSL1-5), and JI582 (SSL1-6). The former three strains were also temperature-sensitive $\left(\mathrm{Ts}^{-}\right)$for growth on enriched medium.

The wild-type SSL1 gene was identified as part of a 7.4-kb DNA insert from a YCp50 wild-type genomic clone bank, on the basis of its ability to complement the recessive Ts ${ }^{-}$phenotype associated with the SSL1 suppressor strains JJ636, JJ637, and Jj638. A 4.2-kb EcoRI$B a m H I$ DNA fragment was subcloned into the integrating vector YIp5 and used to transform an SSL1 wild-type strain to $\mathrm{Ura}^{+}$. $\mathrm{Ura}^{+}$transformants were then crossed to a $\mathrm{Ts}^{-} \mathrm{Ura}^{-}$SSL1 suppressor strain and subjected to tetrad analysis. All Ura ${ }^{+}$ascospores were $\mathrm{Ts}^{+}$, whereas all $\mathrm{Ura}^{-}$ascospores were $\mathrm{Ts}^{-}$, indicating that the DNA region is derived from the SSL1 locus.

The ability to complement the $\mathrm{Ts}^{-}$phenotype associated with the SSL1 suppressor strains was localized to a 2.5-kb XhoI-PvuII DNA fragment. Also, the presence of this fragment on a YCp50 vector in these suppressor strains reduces the ability of the strains to grow on SDhistidine medium. Both observations are similar to those made about the dominant/recessive nature of these phenotypes in diploid cells (S.P. Miller and T.F. Donahue, unpubl.) and indicated that the $2.5-\mathrm{kb}$ Xhol-PvuII DNA fragment contains the intact SSL1 wild-type gene. The DNA sequence of this fragment is shown in Figure 1. An open reading frame (ORF) of 461 amino acids that begins with an ATG is contained in this sequence and is predicted to encode a protein with a calculated $M_{\mathrm{r}}$ value of 52,289 . Southern analysis showed that this region is unique in the haploid yeast genome (data not shown). Northern analysis of total and poly $(\mathrm{A})^{+}$RNA isolated from wild-type and SSL1 suppressor strains identified a unique $1.5-\mathrm{kb}$ transcript derived from this region (data not shown). Primer extension analysis (data not shown) identified three major transcriptional start sites at -45 , -37 , and -29 relative to the ATG that defines the 461 amino-acid ORF.

One copy of this 461-amino-acid ORF was disrupted in a wild-type diploid strain using the $U R A 3^{+}$gene. The resulting diploid transformants were subjected to tetrad analysis. Among 44 tetrads dissected, 31 showed a segregation pattern of two viable to two inviable spores, whereas 13 tetrads had one viable spore. All viable spores were $\mathrm{Ura}^{-}$, indicating that disruption of this ORF results in cell inviability. The lethal effect of this gene disruption can be rescued by first transforming this diploid strain with a $L E U 2^{+}, C E N 4$ plasmid that either contained the 4.2-kb EcoRI-BamHI DNA fragment or the 461-amino-acid ORF under the control of a galactoseinducible promoter. Antibodies directed against the carboxyl terminus-coding region of this ORF, as part of a 
XhOI
CTCGAGGTACTTACGGAACAACT

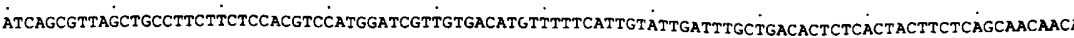

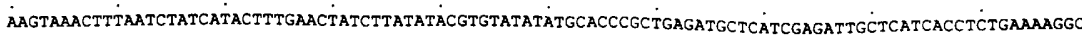
TGTCTGTCACCACCATGTTTTCCGCCGGACCAAATGACAGTTCCTTAAGgGAAACTCAAAGAGACTATATTAACTAAGGAGGATCAACCAGATATGCAAA

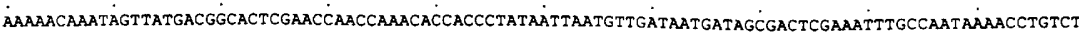
ATTACGCGTCATCTACTTGAGAGTAATATACTGGAAGTTCGAGATACTCCGCACAGGGTCTGGGTGGTAGGTTTCTTTGCTATTGTATAGTTTTTCAAGA

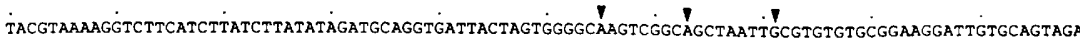$$
1
$$
ATGGCTCCTGTAGTTATTTCAGAATCTGAAGAGGATGAGGATAGAGTTGCCATTACTAGAAGAACTAAGAGACAAGTTCATTTTGATGGCGAGGGAGATGAT

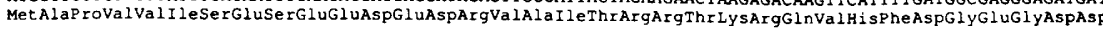
35 CGTGTAGACCAACAGCAACAGCAGCACAGTTCAAGCCACAGGGATAGGGATAAACATGTGCAGCGTAAGAAGAAGAAAAGGCTCTCGAATAGAAACCTGCAA 69 GGTTCAAATGGTGGGTACGCTTGGGAGGATGAGATCAAGAGAAGTTGGGATTTGGTGAAAGTGGACGATGAAGGGGATATGGCATCTCTTGTGGCTAGCATA

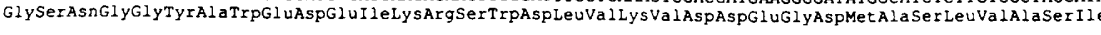
103 GTCGAGGCCAGAAAGAAACGTACTGCTAAGAAAAACATAACGCCATACCAAAGAGGTATTATCAGAAGTTTAATATTAACACTAGATTGMAGTGAAGCTATG

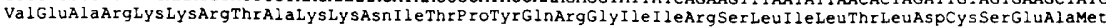
137 TTGGAAAAGGATTTGAGACCAAACAGGCATGCCATGATTATCCAGTACGCCATAGATTTTGTCCATGAATTTTTCGACCAAAATCCGATATCTCAAATGGGT

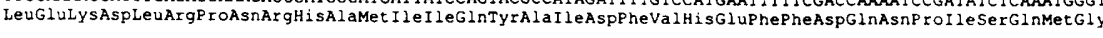
171 ATTATCATAATGAGAAACGGTTTGGCACAACTGGTCAGCCAAGTTAGCGGAAACCCGCAGGATCACATTGATGCGTTGAAATCCATCAGGAAACAAGAACCG

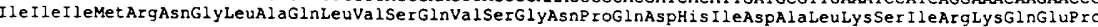
205 AAAGGAAACCCTTCATTGCAAAATGCATTGGAAATGGCAAGAGGCCTTTTATTGCCTGTTCCTGCGCATTGTACAAGGGAAGTACTGATTGTATTTGGTAG?

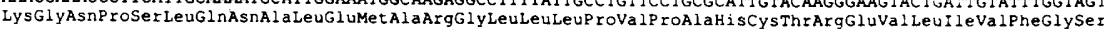
239
CTTTCCACAACTGATCCTGGAGATATTCACCAAACTATCGATTCGTTAGTTTCTGAGAAAATTAGAGTGAAGGTTTTGGGGTTATCAGCTCAAGTGGCCATA 239
CTITCCACAACTGATCCTGGAGATATTCACCAAACTATCGATTCGTTAGTTTCTGAGAAAATTAGAGTGAAGGTTTTGGGGTTATCAGCTCAAGTGGCCATA LeuSerThrThrAspP roGlyAspIleHisGInThrIleAspSerLeuValSerGluLysIleArgValLysValLeuGLyLeuSezAlaGlnValAlaIle 273 TGTAAAGAATTATGCAAGGCAACGAATTATGGTGATGAATCCTICTATAAAATTTTACTCGATGAAACTCACTTAAAGGAGCTATTTAACGAGGCTGTTACC

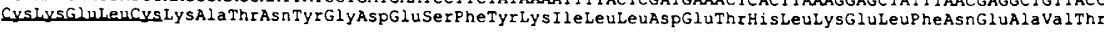
307 CCTTTACCCGTTAACAAAATTAATAAGGGTTTCACACTCGTAAAGATGGGGTTTCCGACAAGGATATTCGAAGATACTCCAACTTTTTGTTCGTGCCATTCC 341 AAGTTAGTTTACGGCGGATACTTCTGTCCCAATTGTCATAGTAAAGTTTGTTCATTGCCCACAGTCTGTCCATGTTGTGACTTGATGCTAATCCTTTCTACC

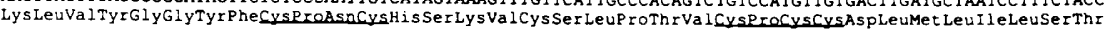
375 CACCTGGCCAGATCATATCACCATCTGATGCCGTTAAAAACATTTGCAGAAGTACCTACAACAGAAAAATTTCGATCAGAAGACTGCTTTAGTTGCCAGTCA HisLeuAlaArgSerTyrHisHisLeuMetP roleuLys ThrPheAlaGluValP IOThrThrGluLysPheArgSerGluAspCysPheSerCysGinser 409

AGATTTCCCATACTGAAAAACCATAAAAATGGTAAACTACTGACAAGTTCTCGCTATCGTTGTGAAGATTGTAAACAAGAATTTTGTGTTGACTGCGATGTG

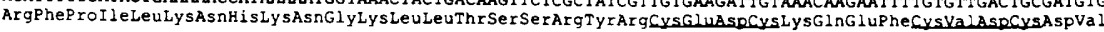
443

TTCATCCATGAAATCCTTCATAACTGCCCAGGCTGTGAATCCAAGCCCGTAATAACTTAACGAAAATCTGTCAGCGTATAACACGATCACTCTTCCATCA PheI leHisGluI le LeuHis AsncysProGlycysGluSerLysProValIleThrTer

ATAACAAATCCAAGTAGTAGAGAACGAAATAGTTTTTGATGgaCATATAACTACATAATTATTACAAAAATAACCTCATTTAATGTCCTATTGTTTATTA CGAGAAAATCTTAATAGCACTTACGGCATTAAGAATATTTATTACTATTTTCAATTTATCAGGCACTTATTCAACTAAAAAAAAAAAAAAAATTCTTTGT TTTACAATAATATTAATAATTATTTTGAATAAATATCGTTACATTCTATCATAATGTCCTCTACACGGTACAACCAAACTCACAATTCTATTTGaGTGGO CGAGAGGTTTGAATTTTTTCTTACTGGGGTGTGTGTAGGGGTCATAGATGTCGCTTGTTTGAATGÄGTGAGGGTTGGAAGGTGCAATAGGTTTCTGTGGA GATtTAaCCAAAACACTGTCGGTCATCCGGCTTTCTCCCTGCTTCCAGCTG
Figure 1. DNA sequence of the wild-type SSL1 gene. The DNA sequence of the 2.5kb XhoI-PvuII DNA fragment was confirmed for both strands. The 461-aminoacid sequence corresponding to the SSL1 gene product is numbered from the ATG $(+1)$. The arrowheads designate the transcriptional start sites that mapped at -45 , $-37,-29$ relative to this first ATG that defines the SSL1 DNA-coding region, as determined by primer extension analysis. The asterisks (left to right) indicate the positions of the nucleotide change found in the SSL1-6 suppressor allele [GAA (Glu) to AAA (Lys); amino acid position + 159], the SSL1.4 mutant allele [TCA (Ser) to TTA (Leu); amino acid position +209], and the SSL1-1 allele [GGG (Gly) to AGG (Arg)] and SSL1-3 mutant allele [GGG (Gly) to CGG (Arg) $)$ the latter two alleles containing different mutations that altered the same amino acid at position +265 in the SSL1 DNA-coding region. Underlined are the eight Cys- $X_{n}$-Cys motifs located in the carboxyl end of the SSL1 DNA-coding region. The nucleotide sequence presented in this paper has been assigned GenBank accession number Z17385.
TrpE fusion protein, detect a protein in yeast extracts with an apparent $M_{\mathrm{r}}$ of $50 \mathrm{kD}$, which is consistent with the calculated $M_{\mathrm{r}}$ of the 461-amino-acid ORF (S.P. Miller and T.F. Donahue, unpubl.). These studies indicate that the intact 461 -amino-acid DNA-coding region is translated in yeast and encodes a protein that is essential for cell viability.

\section{Characterization of the SSL1 suppressor genes}

Each mutation of SSL1 that conferred both the $\mathrm{Ts}^{-}$and the His ${ }^{+}$suppressor phenotypes was mapped by the gap- duplex repair method. A 4.2-kb EcoRI-BamHI DNA fragment as part of YCp50 was restricted at the ClaI site within the 461-amino-acid ORF and used to transform the Ts ${ }^{-}$, SSL1 suppressor strains JJ636, JJ637, and JJ638 to $\mathrm{Ura}^{+}$. Transformation of these strains with intact plasmid yields primarily $\mathrm{Ts}^{+}{ }^{+}$transformants with a weak suppressor phenotype. In contrast, transformation of these strains with plasmid restricted at the ClaI site resulted in a high incidence of $\mathrm{Ts}^{-}$transformants with a stronger $\mathrm{His}^{+}$phenotype. This indicated that the ClaI site was near the site of the mutation that conferred the recessive $\mathrm{Ts}^{-}$and the weak codominant $\mathrm{His}^{+}$suppres- 
sor phenotype. Plasmids were isolated from these $\mathrm{Ts}^{-}$ transformants. In addition, the identical DNA region was isolated from the SSL1 suppressor strains JJ576 and JJ582 by the integration-excision method. The DNA sequence of the entire 461-amino-acid DNA-coding region contained on each of the corresponding plasmids was then determined. Each DNA sequence identified a single-base change that altered an amino acid in this ORF (Fig. 1). The Ts ${ }^{-}$SSL1 suppressor strains JJ636 (SSL1-1) and JJ637 (SSL1-2) each contained the same mutation that altered a glycine (GGG) residue at amino acid position +265 to arginine (AGG), whereas JJ638 (SSL1-3) had a different base change but contained the same glycine (GGG) to arginine (CGG) change at +265. JJ576 (SSL1-4) contained a serine (TCA) to leucine (TTA) change at amino acid +209, whereas JJ582 (SSL1-6) contained a glutamic acid (GAA) to lysine (AAA) change at amino acid position +159 . On the basis of these and the above studies, we conclude that this 461-amino-acid DNA-coding region encodes the $S S L 1$ suppressor gene product.

Searches of DNA and protein data banks did not identify any previously characterized gene or gene product to be related to the SSL1 gene or encoded protein. However, searches did pick out amino acid similarities with a number of zinc finger proteins, because the SSL1 gene product contains a number of sequence motifs common to zinc finger proteins. There are six Cys- $X_{2}$-Cys, one Cys- $X_{3}$-Cys, and one Cys- $X_{2}$-His sequence motifs that are localized to the carboxy-terminal region of the protein (Fig. 1).

\section{SSLl suppression does not alter his4-316 transcription or remove the stem-loop sequence from $m R N A$}

In light of the fact that SSL1 does not correspond in sequence to any previously characterized gene or protein, especially one involved in translation initiation, we characterized the expression of the his4-316 gene in an SSL1-1 strain to gain insight into the mechanism of suppression and the in vivo function of the SSL1 gene product. To address whether alterations in the transcriptional process at his4-316 or removal of the stem-loop sequence from the mRNA were potential mechanisms of SSL1 suppression, we determined the levels, structure, and start position of the his4-316 transcript. As shown in Figure 2A, Northern analysis indicates that the steadystate level of the his4-316 transcript is similar in isogenic $S S L 1^{+}$and SSL1-1 strains. Densitometric scanning of the autoradiograph indicated that the relative ratio of the his4-316 transcript steady-state level to the actin transcript steady-state level was 0.52 in the SSL1 wildtype strain and 0.46 in the SSL1-1 suppressor strain. Comparable ratios of his 4-316 mRNA to actin mRNA were also observed in independent experiments. This suggests that an increase in the level of the his4-316 transcripts is not the mechanism by which SSL1-1 restores a $\mathrm{His}^{+}$phenotype to this strain.

Primer extension analysis of the his4-316 transcripts (Fig. 2B) identified a termination position near the base of the insertion mutation. This does not reflect the start point of the HIS4 transcript, which has been well-documented to initiate 60 nucleotides upstream of the AUG in the wild-type HIS4 allele (Donahue et al. 1982; Nagawa and Fink 1985). Instead, this position, as has been described previously (Cigan et al. 1988; Gulyas and Donahue 1992), reflects the termination position of the primer extension reaction that maps to position $-54,4$ nucleotides upstream from the site of the insertion of the stable stem-loop structure present in the his $4-316$ message. No primer extension product exists either $5^{\prime}$ or $3^{\prime}$ to this termination position, indicating that the his4-316 message derived from the $S S L 1^{+}$and SSL1-1 strains are equivalent, with all molecules possessing a stem-loop structure at the site of the insertion.

SI nuclease protection analysis was performed to assess the start position of the his4-316 transcript in the $S S L 1^{+}$and the SSL1-1 suppressor strains. For these experiments a ${ }^{32} \mathrm{P}$-labeled, single-stranded DNA fragment corresponding to the complementary antisense strand of his4-316 mRNA, including the stem-loop insertion sequence, was used for hybridization. As shown in Figure $2 \mathrm{C}$, two different sized DNA fragments are protected, both of which are identified using RNA isolated from either the $S S L 1^{+}$or the $S S L 1-1$ suppressor strain. The smaller fragment maps an S1 nuclease-sensitive site at 77 nucleotides upstream from the AUG that defines the start of translation at HIS4 (position -77; see Fig. 2C). Presumably this site does not correspond to the $5^{\prime}$ end of the his 4.316 message, because a termination position site at position -77 was not identified by primer extension analysis, but only the site of the insertion at position -54 (Fig. 2B). We believe that the S1 nuclease-sensitive site that maps to position -77 corresponds in position to a site within the stem-loop structure (Fig. 2C). We interpret this result to be attributed to a population of mRNA : DNA duplex that maintains intramolecular base-pair interactions at the site of the insertion such that a stem-loop structure exists in the DNA. The stemloop structure within this DNA therefore provides a single-stranded region that can be cleaved by $\mathrm{S} 1$ nuclease and maps near position -77 (Fig. $2 \mathrm{C}$ ).

The larger protected fragment maps an S1 nucleasesensitive site at 96 nucleotides from the HIS4 AUG start codon (Fig. 2C). This corresponds precisely to the total length of the wild-type HIS 4 leader, 60 nucleotides, and the length of the stem-loop structure, 36-nucleotides. We believe that this is the result of a second population of mRNA : DNA duplexes in the hybridization reaction, which is completely base-paired, including the inserted region of dyad symmetry. S1 cleavage of this duplex therefore identifies the $5^{\prime}$ end of the HIS4 message that is predicted to correspond to position -96 (Fig. 2C) if the stem-loop structure has no effect on the normal transcription initiation process at HIS4. More importantly, the observation that the same two DNA fragments are protected in an SSL1-1 suppressor strain as that found in an $S S L 1^{+}$strain and the apparent ratio of each protected product is also the same (Fig. 2C, cf. the intensity of the -77 vs. the -96 nucleotide protected fragment) illustrates that no change in the his4-316 transcription pat- 
A

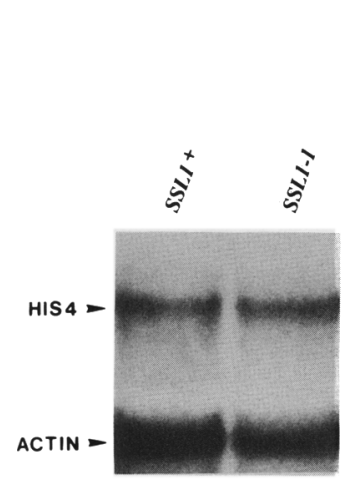

B

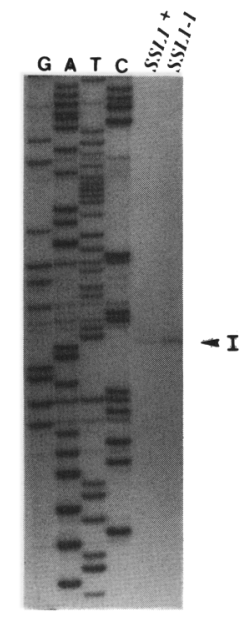

C

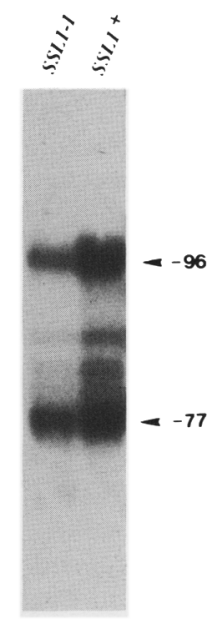

Figure 2. Analysis of his4-316 mRNA from an $S S L 1^{+}$and an $S S L 1-1$ suppressor strain. (A) Northern analysis. Total RNA was prepared from the SSL1 wild-type strain JJ567 and the SSL1-1 suppressor strain JJ636. RNA $(50 \mu \mathrm{g})$ was separated on a $1.0 \%$ agarose gel, transferred to Nytran, and hybridized with ${ }^{32} \mathrm{P}$-labeled probes from the HIS4 DNA-coding region and the actin gene DNA-coding region. $(B)$ Primer extension analysis. Total RNA $(50 \mu \mathrm{g})$ isolated from strains JJ567 (SSL1 ${ }^{+}$) and JJ636 (SSL1-1) was used as a template. The primer and procedure is described in Material and methods and in Cigan et al. (1988). Lanes $G, A, T$, and $C$ represent a DNA sequence ladder generated with the same primer and a plasmid that contains an EcoRI restriction site between positions -51 and -50 in the HIS 4 leader. This plasmid was used as the starting plasmid to construct his 4-316, and the DNA sequence is only used as a marker to map the position of the terminated primer extension reaction. Below the autoradiograph is a schematic interpretation of the primer extension reaction in which the antisense ${ }^{32} \mathrm{P}$ -

labeled oligonucleotide (short thick line), is annealed to the HIS4 DNA-coding sequence and the reverse transcriptase extends the oligonucleotide up to the site of the insertion (I). The products of the reaction detect the presence of the stable stem-loop structure in the his4-316 message, which prevents the identification of the $5^{\prime}$ end of the transcript. $(C)$ S1 nuclease protection analysis. Total RNA was isolated from the wild-type $S S L 1^{+}$strain $1427-15 \mathrm{C}$ and the SSL1-1 suppressor strain 1427-27C. RNA (100 $\mu \mathrm{g}$ each) was hybridized with uniformly, ${ }^{32} \mathrm{P}$-labeled single-stranded DNA that contains the antisense strand of the upstream region of the his4-316 allele, as described in Materials and methods. The resulting hybrids were treated with S1 nuclease, and the S1-resistant fragments were analyzed on an $8 \%$ polyacrylamide sequencing gel. Two major S1 nuclease-protected products are identified. The size of each product was determined from a DNA sequencing ladder that was coelectrophoresed. For clarity, the size of each fragment is interpreted, via the schematic diagram, relative to the position of the AUG codon in the HIS4 DNA-coding region. One product maps an S1 nuclease site at position -77 within the stem-loop structure. The other product maps an S1 nuclease site at position -96 , which is equal in length to the wild-type leader region ( 60 nucleotides) and the insertion sequence (36 nucleotides). For Northern analysis and primer extension and S1 nuclease studies, substitution of total RNA isolated from a his 4 deletion strain showed that all signals are specific to the his4-316 transcript.

tern occurs as a result of SSL1 supppression. Hence, our analysis indicates that the levels, structure, and start position of the his4-316 transcript are similar in SSL1 wildtype, and suppressor strains and suggests that the mechanism of SSL1 suppression is related to a post-transcriptional process.

\section{SSL1 suppression restores HIS4 expression by a post- transcriptional mechanism}

Further evidence that suppression occurs post-transcriptionally was determined by $\beta$-galactosidase assays of extracts prepared from SSL1 wild-type and suppressor strains that contained a his4-316-lacZ fusion construct. As shown in Table 1, extracts derived from SSL1 suppressor strains have higher levels of His4- $\beta$-galactosidase activity than extracts derived from an isogenic $S S L 1$ wild-type strain that contain the same his4-316-lacZ construct. The SSL1-1 and SSL1-3 alleles lead to a higher level of expression, being fivefold above the activity measured from the SSL1 wild-type control strain, whereas SSL1-4 and SSL1-6 result in a threefold increase in expression. In contrast, SSL1 suppression events do not lead to increased levels of $\beta$-galactosidase activity when a wild-type HIS4-lacZ fusion construct is contained in these strains (Table 1). However, two SSL1 suppressor alleles, SSL1-1 and SSL1-3, appear to lower HIS4lacZ expression to $\sim 50 \%$ of the levels detected in an isogenic wild-type strain. We do not understand the basis for this effect. Nevertheless, these assays and our characterization of the his4-316 transcript, as described above, suggest that SSL1 overcomes the inhibitory effects of stem-loop by a post-transcriptional mechanism.

\section{$A \mathrm{Ts}^{-}$, SSL1 suppressor strain has an in vivo polysome defect}

As mentioned previously, three of the SSL1 suppressor strains that we have identified, JJ636 (SSL1-1), JJ637 (SSL1-2), and JJ638 (SSL1-3), are also $\mathrm{Ts}^{-}$for growth on 
Table 1. Efficiency of suppression

\begin{tabular}{|c|c|c|c|c|}
\hline Strain & $\begin{array}{l}\text { Genetic } \\
\text { back- } \\
\text { ground }\end{array}$ & Plasmid & $\begin{array}{l}\beta-\text {-Galactosidase } \\
\text { specific } \\
\text { activity }\end{array}$ & $\begin{array}{l}\text { Fold } \\
\text { increase } \\
\text { over } \\
\text { wild } \\
\text { type }\end{array}$ \\
\hline JJ567 & $S S L 1^{+}$ & his4-316-lacZ & 8 & 1 \\
\hline JJ636 & SSL1-1 & his4-316-lacZ & 43 & 5 \\
\hline JJ638 & SSL1-3 & his4-316-lacZ & 39 & 5 \\
\hline JJ576 & SSL1.4 & his4-316-lacZ & 28 & 3 \\
\hline J582 & SSL1-6 & his4-316-lacZ & 24 & 3 \\
\hline JJ567 & $S S L 1^{+}$ & HIS4-lacZ & 627 & 1 \\
\hline JJ636 & SSL1-1 & HIS4-lacZ & 307 & 0.5 \\
\hline JJ638 & SSL1-3 & HIS4-lacZ & 298 & 0.5 \\
\hline JJ576 & SSL1-4 & HIS4-lacZ & 627 & 1 \\
\hline JJ582 & SSL1-6 & HIS4-lacZ & 583 & 1 \\
\hline
\end{tabular}

enriched medium. On the basis of the genetic selection scheme that we employed, one simple interpretation of the $\mathrm{Ts}^{-}$growth phenotype is that at the restrictive temperature $\left(37^{\circ} \mathrm{C}\right)$, the Ssl1 protein is thermolabile and cannot perform its essential function during the translation initiation process, which leads to the inhibition of protein synthesis and the inhibition of cell growth.

To test this possibility, duplicate cultures of a $\mathrm{Ts}^{-}$, SSL1-1 suppressor strain were grown at the permissive temperature $\left(23^{\circ} \mathrm{C}\right)$, and then one culture was shifted to $37^{\circ} \mathrm{C}$ for an approximate generation time $(2 \mathrm{hr})$. Extracts were prepared from both cultures, fractionated by sucrose gradients, and polysome profiles were compared. Figure $3 \mathrm{~A}$ shows the virtually identical polysome profiles from two extracts prepared from an isogenic SSL1 wild-type strain: One from a culture grown only at $23^{\circ} \mathrm{C}$, and the other from a culture that had been shifted to $37^{\circ} \mathrm{C}$ for $2 \mathrm{hr}$. In contrast, the two polysome profiles derived from an isogenic $\mathrm{Ts}^{-}$, SSL1-1 suppressor strain, JJ636, under the identical growth regimens, are different from each other (Fig. 3B). Although normal polysome profiles are observed when this strain is grown at the permissive temperature, an aberrant profile is observed after this strain is shifted to the restrictive growth temperature. The aberrant profile portrays a reduction in the amount of polysomes and an increased amount of the $80 S$ ribosomal peak, which represents a nonspecific association of accumulated, free $40 \mathrm{~S}$ and $60 \mathrm{~S}$ ribosomal subunits (Yoon and Donahue 1992). This is consistent with the notion that the thermolabile SSL1 gene product cannot perform its essential function in translation initiation. As a result of this block in translation initiation, ribosomes finish translating mRNA but cannot recycle back into the translation process. This leads to a reduction in the number of polysomes and the accumulation of ribosomal subunits, as depicted in the altered profiles at the elevated temperature (Fig. 3). Similar alterations in polysome profiles have also been observed at the restrictive temperature for $\mathrm{Ts}^{-}$mutants that encode other thermolabile gene products involved in translation initiation (Cigan et al. 1991; Yoon and Donahue 1992).
SSLl cell-free extracts exhibit an inherent thermolabile defect in $m R N A$ translation

The polysome defect described above is consistent with the notion that the SSL1 gene encodes an essential component for translation initiation, which is thermolabile as a result of the suppressor mutation. Alternatively, similar results would be expected if the SSL1 suppressor gene encoded a thermolabile transcription factor that regulated the expression of translation initiation components. Perhaps, as a result of the suppressor mutation, Ssll causes the overexpression of an essential translation initiation factor at the permissive temperature, which leads to suppression at HIS4. It would therefore stand to reason that inactivation of the thermolabile Ssl1 protein at the restrictive temperatures would then result in lower levels of the translational component and thus indirectly reduce the translational activity.

To differentiate between these mechanistic interpretations, the in vitro thermolability of cell-free mRNA translation was analyzed with extracts prepared from isogenic wild-type and $\mathrm{Ts}^{-}$, SSL1 suppressor strains grown at the permissive temperature. The logic behind this experiment is that we anticipate that the thermolabile nature of the Ssll protein would be inherent in extracts prepared from cells grown at the permissive

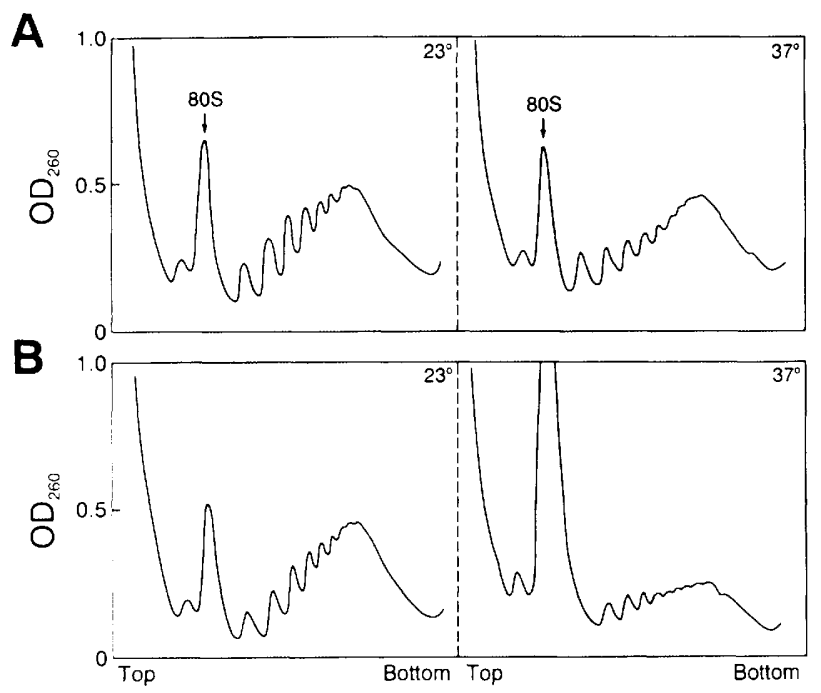

Figure 3. Polysome analysis. Duplicate cultures of either wildtype or $\mathrm{Ts}^{-}$SSL1-1 strains were grown to an $\mathrm{OD}_{600}$ of 1.0 in SD complete medium at $23^{\circ} \mathrm{C}$. One of the duplicate cultures was then shifted to $37^{\circ} \mathrm{C}$, and both the $23^{\circ} \mathrm{C}$ and $37^{\circ} \mathrm{C}$ cultures were incubated for $2 \mathrm{hr}$ more. Cells from each culture were harvested, cell extracts were prepared, and $50 \mathrm{OD}_{260}$ units from each extract was fractionated on a $17-57 \%$ sucrose gradient. Gradients were collected from the top to the bottom using an ISCO 640 density gradient fractionator and monitored by the ISCO UA- 5 absorbance-fluorescence detector. Gradients are plotted as $\mathrm{OD}_{260}$ units versus fraction numbers $(1.2 \mathrm{ml})$ from the top to the bottom of the gradient. $|A|$ Polysome profiles prepared from the $S S L 1^{+}$parent strain JJ567 grown at $23^{\circ} \mathrm{C}$ (left) and $37^{\circ} \mathrm{C}$ (right). (B) Polysome profile of the isogenic Ts- SSL1-1 suppressor strain JJ636 grown at $23^{\circ} \mathrm{C}($ left $)$ and $37^{\circ} \mathrm{C}$ (right). 
temperature. Therefore, only if SSL1 encodes a thermolabile translation factor would the incubation of this extract at an elevated temperature lead to a decrease in its ability to translate exogenously added mRNA. We would not expect that incubation of the extract at elevated temperature would lead to decreased protein synthesis if SSL1 encoded a thermolabile transcription factor. For these experiments, cell-free extracts, depleted of endogenous mRNA with micrococcal nuclease, were preincubated for increasing lengths of time at an elevated temperature and then assayed for the ability to translate exogenously added mRNA. However, this experiment was complicated by the fact that wild-type yeast extracts are inactive for cell-free translation at $37^{\circ} \mathrm{C}$ (Mandel and Trachsel 1989). To circumvent this problem-the extracts were preincubated under less severe temperature conditions $\left(32^{\circ} \mathrm{C}\right)$ and then assayed at $23^{\circ} \mathrm{C}$.

As shown in Figure 4, extracts prepared from isogenic wild-type and Ts - SSL1 suppressor strains differ dramatically from each other in their sensitivity to in vitro heat inactivation. Whereas $\left[{ }^{35} S \mid\right.$ methionine incorporation in a wild-type extract (solid circles) was only moderately affected by preincubation at $32^{\circ} \mathrm{C}$, extracts from the $\mathrm{Ts}^{-}$ suppressor strains SSL1-1 (open squares) and SSL1-3 (open triangles) were strongly inhibited by an identical preincubation treatment. For example, wild-type extracts retained $\sim 80 \%$ of their activity after $6 \mathrm{~min}$ of pre-

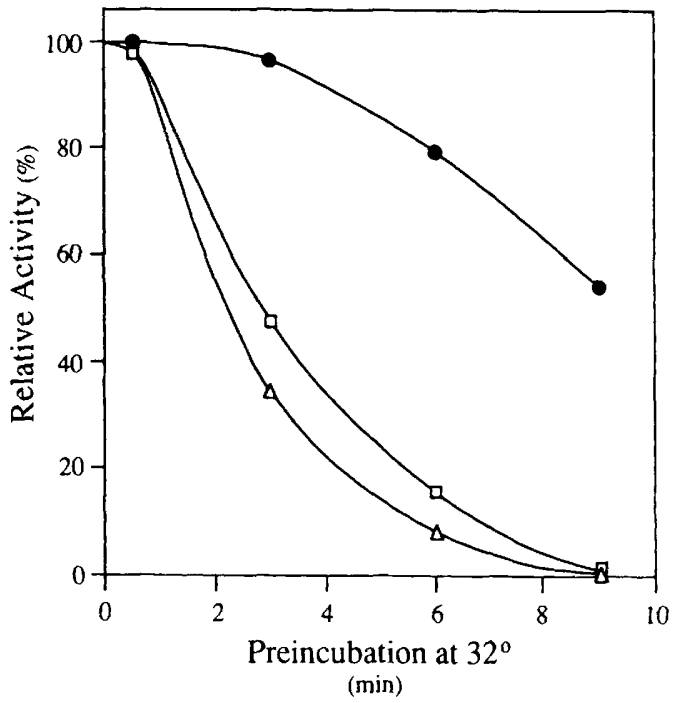

Figure 4. In vitro heat inactivation profiles of cell-free translation extracts from wild-type and SSL1 suppressor strains. Nuclease-treated extracts $(0.45 \mu \mathrm{g})$ from permissive cultures of wild-type (O), SSL1-1 (ㅁ), and SSL1-3 ( $\triangle$ ) strains were preincubated in parallel reactions at $32^{\circ} \mathrm{C}$ for increasing amounts of time as indicated. The extracts were immediately transferred to an incubator and incubated further at $23^{\circ} \mathrm{C}$ with all other components required for mRNA translation. Aliquots $(9 \mu l)$ were removed after $15 \mathrm{~min}$ of incubation and analyzed for hot acidinsoluble radioactivity. The results are expressed as the percent of activity as compared with the unheated control extracts. The $100 \%$ values were $10,105 \mathrm{cpm}$ for wild-type, 9,091 cpm for SSL1-1 and 9,341 cpm for SSL1-3. incubation at $32^{\circ} \mathrm{C}$. In contrast, an identical treatment of an SSL1-1 or SSL1-3 suppressor extract inhibited mRNA translation to $16 \%$ or $8 \%$ of the untreated control extracts, respectively. Moreover, the $\mathrm{Ts}^{-}$SSL1 suppressor extracts were completely inactive after only $9 \mathrm{~min}$ at $32^{\circ} \mathrm{C}$, whereas wild-type extracts retained $\sim 55 \%$ of their original activity. We believe that this difference in thermal sensitivity is not the result of different levels of translational factors in these extracts, as both extracts in the absence of heat treatment are nearly identical in activity (see legend to Fig. 4) and show no difference in sensitivity to $\mathrm{m}^{7}$ GTP inhibition (S.P. Miller and T.F. Donahue, unpubl.). Instead, these results indicate that the thermolability of protein synthesis is an inherent property of the $\mathrm{Ts}^{-}$SSL1 suppressor extracts and agrees with the notion that SSL1 encodes a thermolabile translation factor. It is also worth noting that substitution of poly $(U)$ for total RNA in this experiment did not result in the inhibition of poly(U) translation (S.P. Miller and T.F. Donahue, unpubl.). The $\mathrm{Ts}^{-}$suppressor extracts retained $>95 \%$ of their activity even after $12 \mathrm{~min}$ of preincubation at $32^{\circ} \mathrm{C}$ and were indistinguishable from an isogenic wild-type extract. This seems to illustrate further that the inherent thermolability of protein synthesis in $T^{-}$SSL1 extracts is not the result of a defect in the elongation process but, rather, translation initiation.

Changes in the sequence or position of the stemloop in the HIS4 5' UTR can alter suppression

An important observation obtained from the $\beta$-galactosidase assays is that $S S L 1$ suppressor mutants increase the level of His4 expression when a stem-loop is present in the mRNA but not when the stem-loop is not present (Table 1). This implies that the mechanism of suppression is dependent on having the stem-loop in the mRNA. One interpretation of this result is that the suppressor mutation confers upon Ssll affinity for the stemloop structure that facilitates translation of this message. Alternatively, Ssll does not have newly acquired affinity for the stem-loop but has the general ability to overcome the inhibitory effect of any stem-loop placed in the HIS4 leader, perhaps facilitating a general "unwinding" activity that promotes improved translation of the message.

To gain further insight into the mechanism of SSL1 suppression, we tested whether the $\mathrm{His}^{-}$phenotype caused by the inhibitory effect of stem-loop structures that are either different in sequence or length or located at a different position in the HIS4 leader region was capable of being suppressed by an SSL1 suppressor strain. The his4-316 allele used for the selection of the SSL suppressor mutation contains a 36 -bp insertion sequence that is composed of two repeating units of the sequence 5'-CCCGGATCCGGG-3' flanked by EcoRI restriction sites (Gulyas and Donahue 1992). We therefore increased this insertion to three repeating units to increase the dyad symmetry length (48 nucleotides) and decrease the predicted $\Delta G^{\circ}$ value $(-44.3)$ of the stem-loop between positions -51 and -50 and constructed a strain to con- 
tain this mutation at the HIS4 locus. As shown in Table 2, crosses of this strain (his4-317) to an SSL1 suppressor strain that contains a his4 deletion allele give rise to meiotic ratios of $2^{+}: 2^{-}, 1^{+}: 3^{-}$, and $0^{+}: 4^{-}$on SDhistidine plates. These meiotic ratios are indicative of the ability of SSL1 to act in trans and restore His4 expression despite this alternative stem-loop structure mutation in the leader.

We also constructed yeast strains containing insertion mutations between positions -51 and -50 that deviate significantly in sequence from the repeating sequence unit found in the his4-316 allele but still contain dyad symmetry. One sequence, 5'- GGAATTGTCCTCCTGCCTCCTCCTTAAGGAGGCAGGAGGACAATTCC$3^{\prime}$, was 47 bp in length $\left(\Delta G^{\circ}=-38.1\right)$. This strain (his4318), when crossed with an SSL1 suppressor strain that contains a his 4 deletion, also gave rise to the meiotic ratios $2^{+}: 2^{-}, 1^{+}: 3^{-}$, and $0^{+}: 4^{-}$(Table 2 ), indicative of the ability of SSL1 to restore expression to this his 4 stem-loop mutation strain. However, a third construct, 5'-GGAATTCCGCGCGCGCGATATCGCGCGCGCGGAATTCC-3', failed to be suppressed by SSL1 (Table 2; his4-319), as indicated by only $\mathrm{His}^{-}$meiotic products being identified in crosses to a SSL1 suppressor strain that contains a his 4 deletion. Although this latter sequence resembles the insertion sequence in the his $4-316$ allele in part, the stem is predicted to be richer in contiguous $\mathrm{G}: \mathrm{C} / \mathrm{C}: \mathrm{G}$ base pairs, the loop is predicted to be different in sequence from the his4-316 loop, and the $\Delta \mathrm{G}^{\circ}$ value is lower $(-32.5)$ than that of his $4.316(-27.3)$, although not lower than the $\Delta G^{\circ}$ value calculated for the his4-317(-44.3) and his4-318(-38.1) insertions, both of which are suppressible by SSL1-1. Taken together, these results seem to indicate that there may be flexibility in the mechanism of $S S L 1$ suppression possibly tolerating some changes in the sequence or structure of the stemloop placed between positions -51 and -50 .

To determine whether the position of the stem-loop in the leader was important for the ability of SSL1 to suppress at HIS4, we constructed a strain to contain a stem-loop mutation inserted between positions -27 and -20 in the HIS4 leader such that the stem-loop structure would be located 33 nucleotides downstream from the $5^{\prime}$ end of the message and 20 nucleotides upstream from the AUG start codon. The sequence in- serted at this position was the 36-bp insertion sequence that was used to construct the his $4-316$ allele. When this strain (his4-320) is crossed to an SSL1 suppressor strain that contains a his 4 deletion allele, only $\mathrm{His}^{-}$meiotic products are obtained (Table 2), indicative of the inability of SSL1 to restore His4 expression to this stem-loop mutant. In addition, not only is this insertion sequence derived from the his4-316 allele "nonsuppressible" when located at this downstream site, but reducing this sequence to only one of the repeating core sequences still does not allow SSL1 to restore His4 expression/data not shown). These results suggest that the mechanism of SSL1 suppression may be specific for the position of the stem-loop being nearer the $5^{\prime}$ end of the message.

\section{Two SSL1 suppressor strains exhibit hypersensitivity to UV light}

As mentioned previously, studies in our laboratory also identified the SSL2 gene as a trans-acting suppressor of the stem-loop structure mutation at HIS4 (Gulyas and Donahue 1992). Characterization of SSL2 showed that it is the yeast homolog of the human gene ERCC-3 for which a mutated form was identified in a patient with the DNA repair disease, xeroderma pigmentosum, and clinical symptoms of Cockayne's disease (Weeda et al. 1990). However, SSL2 suppression does not result in removal of the stem-loop sequence from the his4-316 mRNA nor does it confer a defect in DNA repair as measured by increased sensitivity to UV. Only when an SSL2 allele $(S S L 2-X P)$ was constructed to resemble the defective form of the ERCC-3 gene found in a xeroderma pigmentosum patient did yeast become hypersensitive to UV light with $10^{4}$ times more yeast cells killed at UV dosages of $15 \mathrm{~J} / \mathrm{m}^{2}$ or greater as compared with a wildtype strain (Gulyas and Donahue 1992). In crosses between SSL2-1 and SSL1-1 suppressor strains, we noticed that haploid yeast strains containing both suppressor mutations resulted in the loss of the $\mathrm{His}^{+}$suppressor phenotype that is evident in strains containing either suppressor gene (Gulyas and Donahue 1992). This constitutes genetic evidence that the two gene products either interact or function in a related pathway. In light of this functional interaction between the SSL1 and SSL2

Table 2. Tetrad analysis of His ${ }^{-}$, alternative stem-loop strains crossed to SSL1-3, his4 deletion strains

\begin{tabular}{|c|c|c|c|c|c|c|c|c|c|}
\hline \multicolumn{4}{|c|}{ Stem-loop mutation } & \multicolumn{6}{|c|}{$\begin{array}{l}\text { Segregation of } \mathrm{His}^{+} \text {phenotype in tetrads } \\
\text { (3 } 3 \text { spores })\end{array}$} \\
\hline allele & position in leader & length (nucleotides) & $\Delta \mathrm{G}^{\circ}$ & $2^{+}: 1^{-}$ & $1^{+}: 2^{-}$ & $0^{+}: 3^{-}$ & $2^{+}: 2^{-}$ & $1^{+}: 3^{-}$ & $0^{+}: 4^{-}$ \\
\hline his4-317 & $-51 /-50$ & 48 & -44.3 & 1 & 4 & 1 & 5 & 9 & 3 \\
\hline his4-318 & $-51 /-50$ & 47 & -38.1 & 2 & 7 & 9 & 12 & 11 & 6 \\
\hline his4-319 & $-51 /-50$ & 38 & -32.5 & 0 & 0 & 4 & 0 & 0 & 15 \\
\hline his $4-320$ & $-27 /-20$ & 36 & -27.3 & 0 & 0 & 14 & 0 & 0 & 7 \\
\hline
\end{tabular}

The strains containing the alternative stem-loop mutation alleles were EP496 (his4-317), EP1734 (his4-318), EP1751 (his4-319), and CD21 (his4-320) and were analyzed in crosses with either of the his4-401 deletion strains 603-7B or EP1568, both of which contain the SSL1-3 suppressor allele derived from JJ638. 
suppressor genes, we tested whether SSL1 suppressor strains might render yeast cells hypersensitive to UV light.

As shown in Figure 5, two $\mathrm{Ts}^{-} S S L 1$ suppressor strains, JJ636 (SSL1-1) and JJ638 (SSL1-3), are hypersensitive to UV irradiation when compared with the UV sensitivity profile of the isogenic SSL1 wild-type strain JJ567. Although neither suppressor strain is as sensitive to low doses of UV as was the SSL2-XP strain /Gulyas and Donahue 1992), these strains are as hypersensitive to $\mathrm{UV}$ at the highest doses (Fig. 5; 40-60 J/m²) as the SSL2$X P$ strain. In contrast, neither of the isogenic $\mathrm{Ts}^{+}$suppressor strains JJ576 (SSL1-4) nor JJ582 (SSL1-6) is hypersensitive to UV; both are as resistant to UV as the SSL1 ${ }^{+}$ strain (data not shown). It is important to note that although JJ636 and JJ638 have different single-base changes in the SSL1 DNA-coding region, each mutation alters amino acid position +265 from a glycine to an arginine codon (Fig. 2). Hence, the UV-sensitive phenotype observed in both strains is specific for the same amino acid substitution in the SSL1 DNA-coding region.

One difference between JJ636 and JJ638, and the other

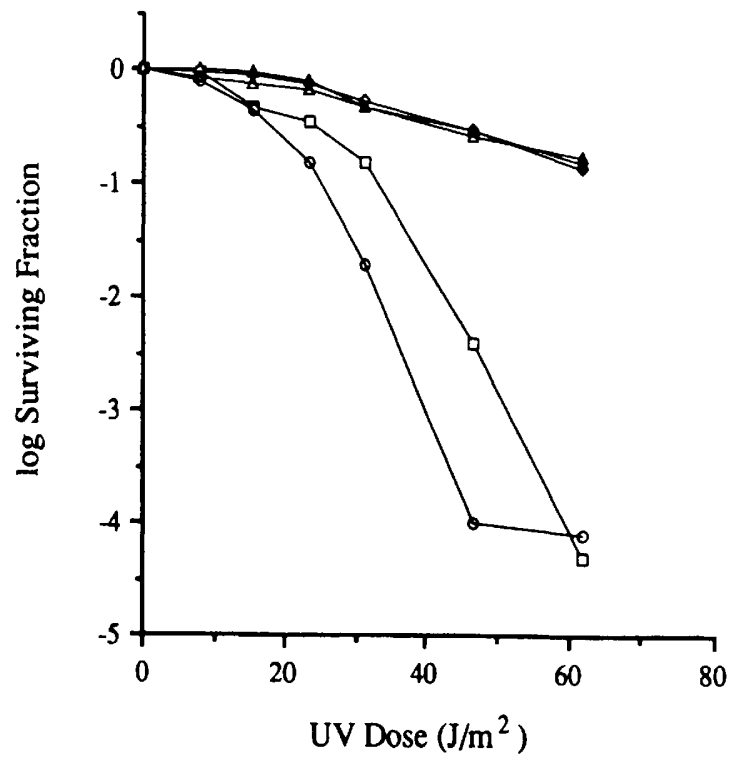

Figure 5. UV-sensitivity profile of SSL1 wild-type and suppressor strains. Cells were grown to stationary phase in liquid YEPD, diluted, and plated onto YEPD plates; sets of plates were then exposed immediately to UV light for various times. UVirradiated cells were incubated overnight in the dark at room temperature and then transferred to a $30^{\circ} \mathrm{C}$ incubator. Colonies were counted and compared with the number of colonies obtained on plates that were not irradiated. The number of colonies was multiplied by the dilution factor and divided by the starting cell population. The log of this fraction (ordinate) was then plotted against the UV dose (abscissa). UV irradiation doses were calculated using the model UVX digital radiometer (UVP, Inc.). Symbols for yeast strains: (A) JJ567 (SSL1+); (D) JJ636

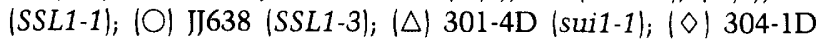
(sui2-1). The UV-sensitivity profiles for strains JJ576 (SSL1-4) and J5582 (SSL1-6) were also assayed and were no different than profiles for strain JJ567, 301-4D, or 304-1D.
Table 3. Phenotypes of strains assayed for UV sensitivity

\begin{tabular}{lcccc}
\hline Strain & $\begin{array}{l}\text { Relevant } \\
\text { allele }\end{array}$ & $\begin{array}{l}\text { Doubling } \\
\text { time (min) }\end{array}$ & $\begin{array}{l}\text { his4-316 } \\
\text { suppression }\end{array}$ & $\begin{array}{l}\text { UV } \\
\text { hyper- } \\
\text { sensitivity }\end{array}$ \\
\hline JJ567 & SSL1 & 90 & - & - \\
JJ636 & SSL1-1 & 128 & + & + \\
JJ638 & SSL1-3 & 132 & + & + \\
JJ576 & SSL1-4 & 102 & + & - \\
JJ582 & SSL1-6 & 102 & + & - \\
301-4D & sui1-1 & 146 & ND & - \\
304-1D & sui2-1 & 161 & ND & -
\end{tabular}

$\mathrm{a}$ (ND) Not determined.

strains, JJ567, JJ576, and JJ582, is that the former two strains grow significantly poorer than the latter strains (Table 3). This led us to speculate that perhaps a mutation in any translation initiation factor that results in an adverse effect on gene expression, as exhibited by poor growth properties, may indirectly confer hypersensitivity to UV to yeast. Perhaps, this may be a result of lowering the level of expression of a protein that is critical/ rate-limiting to the DNA repair process. To test this possibility, we assayed a sui1 and a sui2 mutant for UVhypersensitive phenotypes, each of which contains a mutation in a gene that is important for translation initiation in yeast and confers poor growth properties on the cell. The suil and sui2 mutants were identified in our laboratory as suppressors of initiator codon mutations at the HIS4 locus in yeast (Castilho-Valavicius et al. 1990|. The sui1 suppressor gene encodes a putative translation initiation factor that is essential for the start site selection process in yeast (Yoon and Donahue 1992). The sui2 suppressor gene encodes the $\alpha$-subunit of eIF- 2 that is essential for ternary complex formation /GTPdependent binding of $t \mathrm{RNA}_{i}^{\text {Met }}$ ) and has been implicated genetically to mediate ribosomal recognition of the AUG start codon (Donahue et al. 1988; Cigan et al. 1989; Dever et al. 1992).

As shown in Figure 5, neither the sui1 nor the sui2 suppressor mutant is hypersensitive to $\mathrm{UV}$, with each displaying the same profile observed for the wild-type control strain. More importantly, both the sui1 and sui2 strains grow more poorly than the SSL1-1 and SSL1-3 strains, which showed increased sensitivity to UV/Table 3). Thus, neither a general defect in translation initiation nor poor growth properties as a result of this defect appears to confer a DNA repair defect in yeast as measured by hypersensitivity to UV light. Instead, the UV-hypersensitive phenotype appears to be a direct consequence of specific types of mutations not only in the SSL1 gene but in the SSL2 gene as well.

\section{Discussion}

By using a genetic selection scheme at the HIS4 locus in yeast, we have implicated a novel gene product encoded by the SSL1 gene to be involved in the early steps of translation initiation. The basic strategy of the selection 
scheme is that mutations in components of the translation initiation complex that function in ribosomal binding/scanning of mRNA would bypass the inhibitory effect of a stem-loop structure in the leader region by either promoting unwinding of the secondary structure or allowing the ribosome to bind $3^{\prime}$ to the site of the mutation. The characterization of the SSL1 gene and its mechanism of suppression is in agreement with our selection strategy. The SSL1 gene encodes a gene product that has features suggestive of a protein that might interact with nucleic acids (Fig. 1). It is rich in stretches of basic residues in the amino-terminal end of the protein and contains a number of Cys- $X_{2}$-Cys motifs that are found in proteins known or suspected to interact with RNA or DNA (Berg 1986; Klug and Rhodes 1987). In addition, SSL1 suppressor strains do not appear to alter HIS4 transcription or remove the stem-loop structure either from the HIS4 DNA or mRNA but, rather, suppress the inhibitory effects of the stem-loop mutation by a post-transcriptional mechanism. Most importantly, $\mathrm{Ts}^{-}$SSL1 suppressor strains have thermolabile defects in their polysome profiles and the yeast cell-free in vitro translation system. This constitutes convincing in vivo and in vitro evidence that this protein performs an essential function during translation initiation.

The fact that an SSL1 suppressor strain is capable of suppressing the inhibitory effect of stem-loops when positioned 10 nucleotides downstream from the $5^{\prime}$ end of the message but not when located 33 nucleotides downstream from the $5^{\prime}$ end of the message could suggest that this protein functions at a step that is coincident with ribosomal binding to mRNA. This suggestion seems reasonable if one assumes that 33 nucleotides of leader sequence $5^{\prime}$ to the stem-loop is sufficient to support ribosomal binding to the his 4 message, but the Ssll suppressor protein does not function in the scanning process and therefore cannot overcome the scanning defect imposed by the downstream stem-loop mutation. In addition, we have found that when the stem-loop derived from his4316 is positioned 44 nucleotides downstream of the $5^{\prime}$ end of the message and 36 nucleotides upstream of the AUG, in an artificial HIS4 leader construct, it also cannot be suppressed by SSL1-1 (data not shown). This might also suggest that the ribosome is not simply bypassing the stem-loop by binding $3^{\prime}$ to the stem-loop, as 36 nucleotides is sufficient in length to accommodate a ribosome-binding event (Kozak 1991b). Instead, these results suggest that the mechanism of suppression is dependent on the position of the stem-loop near the $5^{\prime}$ end of the message, perhaps to overcome a mutational block in ribosomal binding at this position.

If Ssll functions in promoting ribosomal binding to mRNA, then we suspect that it functions with the SSL2 gene product in achieving this goal. A number of observations support this suspicion. First, both suppressor genes were isolated by the same selection scheme. Second, the SSL2 suppression spectrum is identical to that observed for the SSL1 suppressor (Tables 1 and 2); SSL2 suppresses the same stem-loop structures positioned near the $5^{\prime}$ end of the HIS4 message but does not suppress stem-loop structures located farther downstream (K.D. Gulyas and T.F. Donahue, unpubl.). Third, and most important, a haploid strain containing both SSL1-1 and SSL2-1 suppressor mutations results in loss of the $\mathrm{His}^{+}$suppressor phenotype, suggestive of two gene products that either interact or function in a related pathway. In addition, this interaction is an allele-specific effect, as it is only observed in strains that contain one of the alleles $S S L 1-1, S S L 1-2$, or $S S L 1-3$, in combination with the SSL2-1 allele (T.F. Donahue, unpubl.); the former three alleles contain the same amino acid substitution in the SSL1 DNA-coding region. In light of these relationships between $S S L 1$ and $S S L 2$, it is tempting to speculate that Ssll might function as an mRNA-binding protein and the RNA helicase-like suppressor gene product Ssl2 functions in unwinding the secondary structure from mRNA. This is reminiscent of the model whereby eIF$4 \mathrm{E}$, the cap binding protein, functions in bringing eIF-4A, the helicase, to mRNA to remove the secondary structure and provide a single-stranded region for the ribosome to bind (Sonenberg 1988; Thach 1992). Alternatively, Ssll could function in a fashion analogous to eIF4B. eIF-4A alone is incapable of unwinding RNA : RNA duplex in vitro in the absence of eIF-4B (Rozen et al. 1990). eIF-4B is thought to provide RNA-binding specificity for eIF-4A to associate with RNA (Milburn et al. 1990; Rozen et al. 1990|. Hence, Ssll could provide mRNA or rRNA-binding activity that allows Ssl2 to associate with mRNA or be in proximity to mRNA to promote unwinding activity.

One surprising outcome of our analysis is the observation that specific alleles of SSL1 confer yeast hypersensitive to UV light. This phenotype establishes another functional relationship between the SSL1 and SSL2 gene products, both of which apparently play an important role in the DNA repair process. This represents an enigma in our analysis as we have not yet resolved the functional connection as to how mutations in both genes can result in either suppression of stem-loop structures in the HIS4 leader or a DNA repair defect in yeast. However, we can envision three possible mechanistic models that would relate these diverse phenotypes. Unfortunately, none of the mechanisms can be supported unequivocally by the available data. One possible explanation for these results is that both genes function only in DNA repair. We offer this model, as it has been speculated that the RNA : DNA duplex displacement activity observed with the $R A D 3$ gene product might be related to removing mRNA that is being transcribed from damaged single-stranded template DNA to facilitate DNA repair (Bailly et al. 1991). Suppressor mutations in either gene would therefore result in an Ssl1-Ssl2 complex acquiring the totally new function of unwinding mRNA to remove the secondary structure that leads to suppression at HIS4. Although we cannot rule out this possibility for Ssl2, as it has not been directly implicated in translation, it seems rather remote for Ssl1, as we have compelling evidence that this gene product is directly involved in protein synthesis; Ts $^{-}$, SSL1 suppressor strains have in 
vivo and in vitro defects in translation initiation (Figs. 3 and 4; S.P. Miller and T.F. Donahue, unpubl.).

A second possibility is that both Ssl1 and Ssl2 have dual functions: a function in translation initiation that is essential for cell viability, and a second function in DNA repair that is not essential for viability. As a complex in the nucleus, Ssll and Ssl2 might function in the DNA repair process; and as a complex in the cytoplasm, both function in the translation initiation process. This is a very interesting possibility, and we have no data to refute this potential mechanism. The observation that a specific deletion mutation in the SSL2 gene (SSL2-XP), made to resemble the mutation identified in the ERCC-3 gene of a xeroderma pigmentosum patient, was necessary to render a DNA repair defect in yeast could suggest that a specific region of the protein is dedicated solely to interacting with DNA or participating in the DNA repair process.

A third possible mechanism as to why mutations in SSL1 and SSL2 suppress stem-loop structure mutations and affect DNA repair is that both gene products only function in translation initiation and control the expression of DNA repair genes. Of all the possible mechanisms put forth, an alteration in gene expression that impacts on DNA repair would appear to be the most conventional explanation for the "connection" between suppression and UV hypersensitivity. The only requirement that needs to be imposed is that a DNA repair gene or a gene that controls the expression of a DNA repair gene must be subject to translational control. The observation that a single mutation in SSL1 affects both DNA repair and translation initiation may mean that both phenotypes have a common functional denominator. On the other hand, the observation that $S S L 2-X P$ has such a drastic consequence on DNA repair but does not significantly impair the growth of yeast (Gulyas and Donahue 1992), as might be expected of a mutation that would alter translation initiation, clouds a clear understanding of how DNA repair might be linked to translation initiation. However, one possible explanation for this observation is that Ssll might play a more general role in translation initiation, with one of its roles being the control of expression of a DNA repair gene. Ssl2 also might play an important part in translation, but with its action limited to a subset of mRNAs, including a DNA repair enzyme. This might explain why a complete deletion of this gene is lethal to yeast but a specific mutation might affect only DNA repair-a limited region of this protein perhaps dedicated to promote an interaction with a region of mRNA that encodes a DNA repair enzyme. This raises the intriguing possibility that the expression of some mRNAs may be controlled by specific secondary structures and that Ssl1 and Ssl2 function in removing such structures. In essence, not all mRNAs are created equal at the translational level. Hence, the translation of standard mRNAs may be more dependent on eIF-4F, for example, whereas less standard mRNAs may be more dependent on Ssl1 and Ssl2. Therefore, by putting a secondary structure in the HIS4 message and selecting for expression, we have demanded that factors that nor- mally remove specific secondary structures in some mRNAs acquire a new specificity for the stem-loop at HIS4. If this proves to be the case, it would seem that the genetics of yeast has provided a powerful approach to the discovery of a translational regulatory mechanism that is not apparent by straightforward biochemical approaches. In any case, our genetic studies appear to have been effective in identifying a novel translation factor that is essential for the early steps of translation initiation.

\section{Materials and methods}

\section{Yeast strains and genetic methods}

The yeast strains used in this analysis are related to TD28 (MATa ura3-52 ino1-13), a derivative of yeast strain S288C (MAT $\alpha$ ). Standard genetic techniques and media used for our analysis have been described (Sherman et al. 1979). The SSL1 suppressor strains JJ576 (SSL1-4), JJ578 (SSL1-5), JJ582 (SSL1-6), JJ636 (SSL1-1), JJ637 (SSL1-2), and JJ638 (SSL1-3) were identified in the same fashion as that reported for the SSL2 suppressor strain (Gulyas and Donahue 1992; S.P. Miller and T.F. Donahue, unpubl.).

For quantitating the effects of SSL1 suppression events on His4 expression, in-frame HIS4-lacZ and his4-316-lacZ fusion genes as part of YCp50 were each used to transform the isogenic strains JJ567 (SSL1+), JJ576 (SSL1-4), JJ582 (SSL1-6), JJ636 (SSL11), and JJ638 (SSL1-3) to Ura ${ }^{+}$. The construction of these plasmids has been described previously (Cigan et al. 1988) and contains all $5^{\prime}$ noncoding sequences that are necessary for the transcription and regulation of HIS4 expression. Strains were grown in SD medium lacking uracil, and extracts were prepared and assayed for $\beta$-galactosidase activities as described previously (Donahue and Cigan 1988).

Construction of the yeast strain containing the his4-317 secondary structure allele (previously referred to as $-51 /-50 \mathrm{~B} 3$ ) has been described (Cigan et al. 1988). Yeast strains containing the alternative secondary structure alleles his4-318 and his4319 were constructed in the identical fashion as strains containing the his4-316 and his4-317 alleles (Cigan et al. 1988), with the exception that oligonucleotides of different sequences were inserted at the unique EcoRI site located between positions - 51 and -50 in the HIS 4 leader region. Each of the self-complementary oligonucleotides 5'-AATTGTCCTCCTGCCTCCTCCTTAAGGAGGCAGGAGGAC-3' and $5^{\prime}$-AATTCCGCGCGCGCGATATCGCGCGCGCGG-3' was used to construct the his4318 and his4-319 alleles, respectively. A yeast strain containing the his4-320 allele was constructed by first introducing a unique EcoRI site in the HIS4 leader by site-directed mutagenesis. The oligonucleotide 5'-TAATACAAGGAATTCCAAAATTT3 ' was used for this experiment and results in changing the sequence of positions -27 to -20 in the HIS4 leader from TAGTTTAC to GGAATTCC. This allowed us to introduce the 36-bp insertion sequence contained in the his4-316 allele, via the unique EcoRI site, to a position more $3^{\prime}$ in the HIS4 leader. The methods employed for this construction and the subsequent construction of yeast strains containing the his $4-320$ allele are the same as described previously for other site-directed and insertion mutagenesis studies of the HIS4 leader region (Cigan et al. 1988). The presence and number of inserts in the HIS4 region were confirmed either by Maxam and Gilbert DNA sequencing (1980) or by the double-stranded chain-termination method (Sanger et al. 1977). $\Delta \mathrm{G}^{\circ}$ values of the stem-loop structures were calculated using the Zuker and Jaeger MULFOLD computer program (Jaeger et al. 1989). The ability of SSL1 to sup- 
press the alternative stem-loop structure mutants, EP496 (Mata his4-317 ura3-52 ino1-13), EP1734 (Mata his4-318 ura3-52 ino1. 13), EP1751 (Mata his4-319 ura3-52 ino1-13), and CD21 (Mata his4-320 ura3-52 ino1-13) was assessed by tetrad analysis from crosses with either of the his4 deletions strains 603-7B (Mat $\alpha$ SSL1-3 his4-401 leu2-3,-112 ino1-13) or EP1568 (Mata SSL1-3 his4-401 ura3-52 leu2-3,-112); the latter two strains contain the SSL1-3 suppressor allele that was derived from mutant J)638.

UV sensitivity of yeast strains JJ567 (SSL1 ${ }^{+}$), JJ576 (SSL1-4), JJ582 (SSL1-6), JJ636 (SSL1-1), JJ638 (SSL1-3), 301-4D (Mata sui1-1 his4-303 ura3-52 leu2-3,-112), and 304-1D (Mata sui2-1 his4-303 ura3-52) was measured as described previously (Gulyas and Donahue 1992). The genetic, molecular, and biochemical characterizations of the sui1-1 and sui2-1 strains used in these experiments have been reported previously (Cigan et al. 1989; Castilho-Valavicius et al. 1990; Yoon and Donahue 1992). The data presented in Figure 5 represent the average of two independent experiments, with each data point being the average of four plates per UV dosage.

\section{Isolation and characterization of wild-type} and mutant SSL1 alleles

The wild-type SSL1 gene was cloned from a YCp50 wild-type genomic clone bank (Rose et al. 1987). Four positive clones were identified on the basis of complementation of the recessive Ts ${ }^{-}$ phenotype associated with yeast strains $555-8 \mathrm{C}$ (SSL1-1), 5564B (Mata SSL1-2 his4-316 ura3-52 ino1-13), or 557-4B (SSL1-3), which are ascospore derivatives of SSL1 suppressor strains, JJ636, JJ637, and JJ638, respectively. Restriction analysis of these clones indicated that the inserts were related and derived from the same chromosomal location. The smallest clone, which contained a Sau3A DNA insert of $\sim 7.4 \mathrm{~kb}$ was used for subsequent characterizations of the wild-type SSL1 gene.

To establish that the cloned DNA fragments were derived from the SSL1 chromosomal region, a 4.2-kb EcoRI-BamHI DNA fragment was subcloned into the EcoRI and BamHI sites of the integrating plasmid YIp5 to generate plasmid p1030. Plasmid p1030 was then restricted at the unique ClaI site (Fig. 1), which resides in the SSL1 DNA-coding region, and this linearized plasmid was used to transform the wild-type SSL1 strain JJ567 to $\mathrm{Ura}^{+}$. Ura ${ }^{+}$transformants were then crossed to the $\mathrm{Ura}^{-}{ }^{-} \mathrm{Ts}^{-}$SSL1 suppressor strain 556-4D (Mata SSL1-2 his4316 ura3-52 ino1-13), an ascospore derivative of JJ637, and diploids were analyzed by tetrad analysis. Subcloning experiments for localization of the wild-type SSL1 gene were performed with the yeast single-copy $U R A 3$ plasmid YCp50. The $S S L 1$ gene was localized to a XhoHl-BamHI fragment of $\sim 3.0 \mathrm{~kb}$. Subsequent removal of the small $0.3-\mathrm{kb}$ PvuII fragment contained in the distal end of this region was shown not to affect its ability to complement the $\mathrm{Ts}^{-}$phenotype associated with SSL1 suppressor strains. This allowed us to localize the SSL1 wild-type gene to reside on the $2.5-\mathrm{kb}$ XhoI-PvuII DNA fragment (Fig.1). The complete DNA sequence of this fragment was determined for both strands.

A YCp50 plasmid, p1023, containing the wild-type SSL1 gene as part of a 4.2-kb EcoRI-BamHI fragment, was used to isolate the $\mathrm{Ts}^{-}$SSL1 suppressor alleles by the gap-duplex repair method (Orr-Weaver et al. 1983). p1023 was restricted at the ClaI site located within the coding region of the SSL1 gene (Fig. 1). The Ts ${ }^{-}$SSL1 suppressor strains JJ636, JJ637, and JJ638 were transformed with the linearized plasmid, and $\mathrm{Ura}^{+} \mathrm{Ts}^{-}$transformants with a His ${ }^{+}$phenotype, indicative of the presence of an SSL1 suppressor mutation on the plasmid, were used to isolate SSL1 mutant alleles. The identical DNA region was iso- lated from the Ts ${ }^{+}$SSL1 suppressor strains JJ576 and JJ582 by the integration and excision method (Winston et al. 1983). For these experiments plasmid p967 was used, which contains an EcoRI-ClaI DNA fragment of $\sim 2.6 \mathrm{~kb}$ in YIp5. The presence of a single mutation in each of the SSL1 suppressor alleles was confirmed by DNA sequence analysis of the entire SSL1 DNAcoding region.

\section{Analysis of SSLl expression}

Plasmid pl022 was constructed to perform gene disruption experiments (Rothstein 1983) of the $S S L 1^{+}$DNA-coding region. This plasmid contains the $4.2-\mathrm{kb}$ EcoRI-BamHI fragment ligated into the EcoRI and BamHI site of pBR322. This plasmid was restricted at the unique ClaI site in the SSL1 DNA-coding region, and the site was blunt ended using reverse transcriptase and dNTPs. The HindIII ends of a 1.1-kb DNA fragment containing the $U R A 3^{+}$gene were blunt ended by the same procedure, and this fragment was ligated into the blunt ended ClaI site of plasmid p1022 to generate plasmid p1029. Plasmid p1029 was then restricted with EcoRI and BamHI. This fragment contains the SSL1 wild-type gene disrupted by the $U R A 3^{+}$gene and was used to transform the diploid strain EKP81 (Mata/Mata his 4-316/his4-316 ura3-52/ura3-52 leu2-3,-112/leu2-3,-112) to $\mathrm{Ura}^{+}$. Two transformant EKP99 and EKP105 strains were confirmed by Southern analysis to contain an intact copy of the SSL1 gene and an SSL1::URA $3^{+}$disruption allele. EKP99 and EKP105 strains were sporulated and analyzed by tetrad analysis. For Southern blotting, a ${ }^{32}$ P-labeled probe complementary to the SSL1 DNA-coding region was generated using the universal primer and a M13mpl0 phage that contained the 1.1-kb ClaIPvull fragment.

To determine whether translation of the wild-type SSL1 DNA-coding region could rescue the disrupted SSL1::URA3 ${ }^{+}$ allele, plasmid p1375 was constructed by first ligating an EcoRI-BamHI fragment of $\sim 820$ bp containing the GALlGAL10 promoter and regulatory region (Johnston and Davis 1984 ) into the corresponding restriction sites of the LEU2 ${ }^{+}$, CEN4 vector pSB32 (Rose and Broach 1991) to generate plasmid pl345. A BamHI restriction site was introduced 9 nucleotides upstream from the ATG codon that defines the start of translation of the SSL1 DNA-coding region by site-directed mutagenesis. This allowed us to subclone the entire SSL1 DNA-coding region and distal sequences as part of a $2.5-\mathrm{kb} B a m H I$ DNA fragment into the BamHI site of plasmid pl345 such that the transcription of the SSL1 DNA-coding region was under the control of the galactose-inducible GAL1 promoter region. This plasmid, p1375, was then used to transform the SSL1::URA3 ${ }^{+}$ diploid strains EKP99 and EKP105 to Leu ${ }^{+}$. Transformants were sporulated and dissected on either YEPD or YEP galactose (YEPGal) plates. Antibodies directed against the SSL1 gene product were generated from a TrpE-Ssll fusion protein expressed in Escherichia coli. The SSL1 ${ }^{+}$DNA-coding region from amino acid +251 to +461 contained on a $2.0-\mathrm{kb}$ ClaI-BamI DNA fragment was fused in-frame to the carboxyl end of the $\operatorname{trp} E$ DNA-coding region in the pATH3 expression vector (Dieckmann and Tzagoloff 1985). The methods used for inducing the expression of the trpE-SSL1 plasmid (p986) in E. coli, extracting the antigen, and immunizations have been reported (Donahue et al. 1988).

\section{RNA analysis}

Northern blot, primer extension, and S1 nuclease protection analysis were performed with total RNA. The procedure for RNA isolation has been described previously (Cigan et al. 1988). 
For Northern analysis of the SSL1 transcript, RNA was isolated from the SSL1 wild-type strain 1427-15C (Mata his4-316 ura352) and the SSL1 supressor strain 1427-27C (Mata SSL1-1 his4316 ura3-52). A ${ }^{32}$ P-labeled probe was generated from the $2.0-\mathrm{kb}$ KpnI-ClaI DNA fragment containing the upstream wild-type SSL1 DNA-coding region. Northern analysis of the his $4-316$ transcript was performed with RNA isolated from the wild-type SSL1 strain IJ567 and the isogenic SSL1-1 suppressor strain Jj636. The HIS4 probe was derived from a $2.7-\mathrm{kb}$ EcoRI fragment that encodes the downstream HIS4 DNA-coding region (Donahue et al. 1982). As an internal control for the his4-316 Northern analyses, filters were washed of counts and incubated with a probe from a 3.0-kb EcoRI-BamHI fragment containing the entire actin gene DNA-coding region. All probes were made by the random primer method, and $50 \mu \mathrm{g}$ of RNA was probed from each strain. Conditions for Northern blots have been reported (Donahue et al. 1983).

For primer extension analysis of the $S S L 1^{+}$transcript, $10 \mu \mathrm{g}$ of poly $(\mathrm{A})^{+}$RNA from strain EP831 was hybridized with an oligonucleotide, 5'-CCCTCGCCATCAAAATG-3', which is complementary to positions +79 to +95 in the SSL1 DNAcoding region. This strain contains the SSL1 gene on a high-copy plasmid, as described above, and was used for this experiment, as we could not detect an extension product with RNA isolated from a single-copy SSL1 strain, presumably owing to the low abundance of the transcript. For primer extension analysis of the his4-316 transcript, $50 \mu \mathrm{g}$ of total RNA, isolated from strains JJ567 $\left(S S L 1^{+}\right)$and JJ636 (SSL1-1) was incubated with the oligonucleotide 5 -CATCAATTAACGGTAGAATCGG-3', which is complementary to position +10 to +31 in the HIS4 DNA-coding region. The conditions for primer extension have been described previously (Cigan et al. 1988), except that 6 units of AMV reverse transcriptase was used for each analysis and primer extension reactions were incubated at $42^{\circ} \mathrm{C}$ for $90 \mathrm{~min}$.

S1 nuclease protection experiments of the his4-316 transcript were performed as described by Burke (1984), with minor modifications. A single-stranded DNA template was constructed by subcloning a 796-bp PvuII-XhoI fragment from the upstream region of the his4-316 allele into the SmaI and SalI sites of phage vector M13mp18. This template (mpl8::his4-316) contains $\sim 100$ nucleotides of the HIS4 DNA-coding region, a 96 nucleotides 5'-UTR inclusive of the inserted region of dyad symmetry (his4-316 mutation), and $\sim 600$ nucleotides of the HIS4 promoter and regulatory region (Donahue et al. 1982; Cigan et al. 1988). Primer annealing was performed by heating the template (750 $\mathrm{ng}$ ) and M13 universal sequencing primer (50 $\mathrm{ng}$ ) in a $50 \mu \mathrm{l}$ reaction mixture at $90^{\circ} \mathrm{C}$ for $3 \mathrm{~min}$ and then cooling slowly to room temperature. At the end of incubation, unlabeled dATP, dGTP, and dTTP at a final concentration of $100 \mu \mathrm{M}$ were added. To prepare the probe, 10 pmoles of $\left[\alpha^{-32} \mathrm{P}\right] \mathrm{dCTP}(3000 \mathrm{Ci} /$ mmole) and 1.0 unit of DNA polymerase I (Klenow fragment) were added to the primer annealed template and incubated for $20 \mathrm{~min}$ at room temperature. The synthesis was chased by the addition of $1 \mu \mathrm{l}$ of $10 \mathrm{mM} \mathrm{dCTP}$ and incubated further for $20 \mathrm{~min}$ at room temperature. The reaction was stopped by heat inactivation at $65^{\circ} \mathrm{C}$ for $15 \mathrm{~min}$. Probe labeled with ${ }^{32} \mathrm{P}$ was digested with PvuII, and the single-stranded probe was isolated by electrophoresis of the restriction digest on a $4 \%$ polyacrylamide strand separation gel containing 8 murea. Single-stranded probe was hybridized with total RNA (100 $\mu \mathrm{g})$ in a buffer containing $40 \mathrm{~mm}$ PIPES ( $\mathrm{pH} 6.4$ ), $1 \mathrm{~mm}$ EDTA, $0.4 \mathrm{M} \mathrm{NaCl}$, and $80 \%$ deionized formamide at $80^{\circ} \mathrm{C}$ for $10 \mathrm{~min}$ and then incubated for $16 \mathrm{hr}$ at $42^{\circ} \mathrm{C}$. The hybridization mixture was incubated for 30 min at $37^{\circ} \mathrm{C}$ with 100 units of S1 nuclease in $150 \mu$ l of Sl buffer (250 mM NaCl, $30 \mathrm{~mm}$ sodium acetate at $\mathrm{pH} 4.6,4.5 \mathrm{~mm}$ zinc sulfate, $20 \mu \mathrm{g}$ of sonicated calf thymus DNA|. S1 nuclease di- gestions were terminated by the addition of $0.5 \mathrm{M}$ ammonium acetate, $10 \mathrm{mM}$ EDTA, and $5 \mu \mathrm{g}$ of tRNA and then ethanol precipitated. S1-protected fragments were analyzed on $8 \%$ polyacrylamide sequencing gels with a sequencing ladder generated from mpl8::his4 and the universal primer.

\section{Polysome analysis}

Polysome profiles of the Ts ${ }^{-}$SSL1-1 strain JJ636 were analyzed from cultures incubated under permissive $\left(23^{\circ} \mathrm{C}\right)$ and restrictive $\left(37^{\circ} \mathrm{C}\right)$ temperature conditions and compared with those of the isogenic $S S L 1^{+}$parent strain JJ567. The growth conditions and methods used to prepare extracts and polysomes from wild-type and SSL1 suppressor strains are identical to those described previously (Yoon and Donahue 1992), with the exception of two modifications: Cells were grown in SD complete medium, as the $\mathrm{Ts}^{-}$effect was more pronounced in this medium than in YEPD medium; and $17-57 \%$ sucrose gradient conditions were used to enhance the resolution of the polysomes.

\section{Cell-free translation}

The SSL1 suppressor strains JJ636 (SSL1-1) and JJ638 (SSL1-3) were analyzed in a cell-free translation system in comparison to the isogenic parent strain JJ567 $\left(S S L 1^{+}\right)$. Cells were grown at $28^{\circ} \mathrm{C}$ to an $\mathrm{OD}_{600}$ of $\sim 1.0$ in 1 liter of YEPD, harvested, and washed; cell-free extracts were then prepared in parallel from each culture, as described by Hofbauer et al. (1982). Protein concentrations were determined spectrophotometrically (Groves et al. 1968), with bovine serum albumin as a standard.

The two-step incubation procedure (Gasior et al. 1979) was employed to assay cell-free translation of mRNA. In the first step, endogenous mRNA was digested by treating the extracts $(10 \mathrm{mg} / \mathrm{ml}$ of protein) with $20-40 \mu \mathrm{g} / \mathrm{ml}$ of micrococcal $\mathrm{nu}-$ clease (Sigma) in the presence of $1 \mathrm{mM} \mathrm{CaCl}{ }_{2}$. After 10-12 min at $23^{\circ} \mathrm{C}$ the reactions were placed on ice and then stopped by the addition of EGTA $(\mathrm{pH} 7.5)$ to a final concentration of $2 \mathrm{~mm}$. In the second step, aliquots $(45 \mu \mathrm{l})$ from the mRNA-depleted extracts were incubated with all of the components required for protein synthesis, including total yeast RNA and a radioactive amino acid. The final reaction mixtures $(75 \mu \mathrm{l})$ contained 0.45 $\mathrm{mg}$ of nuclease-treated extract, $60 \mathrm{~mm}$ HEPES-KOH $(\mathrm{pH} 7.5)$, $160 \mathrm{~mm} \mathrm{KO}-\mathrm{Ac}, 3 \mathrm{~mm} \mathrm{Mg}(\mathrm{O}-\mathrm{Ac})_{2}, 3 \mathrm{~mm}$ dithiothreitol, $0.5 \mathrm{~mm}$ ATP, $0.1 \mathrm{mM}$ GTP, $2 \mathrm{~mm}$ glucose- 6 -phosphate, $20 \mathrm{~mm}$ creatine phosphate, $5 \mu \mathrm{g}$ of creatine phosphokinase, $50 \mathrm{~mm}$ each of 19 unlabeled amino acids (omitting methionine), $20 \mu \mathrm{g}$ of total yeast RNA, and $0.3 \mu \mathrm{M} \mathrm{L}-\left[{ }^{35} \mathrm{~S}\right]$ methionine $(600-1000 \mathrm{Ci} / \mathrm{mole})$. Yeast total RNA was prepared as described previously (Cigan et al. 1988). The incubations were carried out at $23^{\circ} \mathrm{C}$. Aliquots $(9$ $\mu$ ) were removed at various times, and the amount of $\left[{ }^{35} \mathrm{~S}\right] \mathrm{me}$ thionine incorporation into hot $\left(90^{\circ} \mathrm{C}\right) 5 \%$ trichloroacetic acidinsoluble protein was determined as described previously (Hussain and Leibowitz 1986), except that the discs were washed only once with acid following the boiling step.

Cell-free translation of the synthetic template poly $(\mathrm{U})$ was carried out under reaction conditions that measure only polypeptide chain elongation (Gasior et al. 1979). Reaction mixtures (75 $\mathrm{\mu l}$ ) contained $0.45 \mathrm{mg}$ of nuclease-treated extract, $20 \mu \mathrm{g}$ of poly $(\mathrm{U}), 5 \mu \mathrm{g}$ of yeast tRNA ${ }^{\text {Phe }}, 12.5 \mu \mathrm{M} \mathrm{L} \cdot\left[\mathrm{U}-{ }^{14} \mathrm{C} \mid\right.$ phenylalanine plus buffered salts, DTT, ATP, GTP, glucose-6-phosphate, creatine phosphate, and creatine phosphokinase, as described above except that the $\mathrm{Mg}^{2+}$ concentration was increased to 14 $\mathrm{mM}$. The reactions were incubated at $23^{\circ} \mathrm{C}$, and at various times aliquots were removed and analyzed for poly- $\left[{ }^{14} \mathrm{C}\right]$ phenylalanine synthesis by determining the amount of radioactivity that was incorporated into hot acid-insoluble protein as described above. 
The in vitro heat inactivation experiments were performed as described previously (Mandel and Trachsel 1989), with minor modifications. Aliquots $(45 \mu$ l) from the mRNA-depleted extracts $(10 \mathrm{mg} / \mathrm{ml}$ of protein) were preincubated in parallel at $32^{\circ} \mathrm{C}$ for various lengths of time as indicated in Figure 4. Immediately following this preincubation, all of the components required for cell-free translation were added and the reactions 175 $\mu$ l) were then incubated at $23^{\circ} \mathrm{C}$. Aliquots $\{9 \mu 1\}$ were removed from each translation reaction after $5,10,15,20,30$, and $40 \mathrm{~min}$ of incubation and analyzed as described above for hot acid-insoluble radioactivity. For Figure 4, only the 15 -min time point is presented.

\section{Acknowledgments}

We thank members of our laboratory for helpful discussions, Colleen Dixon for technical assistance, Jim Brown for doing the Zuker program analysis, and Peter Cherbas and Mimi Zolan for helpful suggestions on the manuscript. This work was supported by U.S. Public Health Service grant GM32263 from the National Institutes of Health awarded to T.F.D.

The publication costs of this article were defrayed in part by payment of page charges. This article must therefore be hereby marked "advertisement" in accordance with 18 USC section 1734 solely to indicate this fact.

\section{References}

Bailly, V., P. Sung, L. Prakash, and S. Prakash. 1991. DNA : RNA helicase activity of RAD3 protein of Saccharomyces cerevisiae. Proc. Nat1. Acad. Sci. 88: 9712-9716.

Berg, J.M. 1986. Potential metal-binding domains in nucleic acid-binding proteins. Science 232: 485-487.

Burke, J.F. 1984. High-sensitivity S1 mapping with singlestranded $\left[{ }^{32} \mathrm{P}\right] \mathrm{DNA}$ probes synthesized from bacteriophage M13mp templates. Gene 30: 63-68.

Castilho-Valavicius, B., H. Yoon, and T.F. Donahue. 1990. Genetic characterization of the Sacchromyces cerevisiae translational initiation suppressors sui1, sui2 and SUI3 and their effects on HIS4 expression. Genetics 124: 483-495.

Cigan, A.M., E.K. Pabich, and T.F. Donahue. 1988. Mutational analysis of the HIS4 translational initiator region in Sacchromyces cerevisiae. Mol. Cell. Biol. 8: 2964-2975.

Cigan, A.M., E.K. Pabich, L. Feng, and T.F. Donahue. 1989. Yeast translation initiation suppressor sui2 encodes the $\alpha$ subunit of eukaryotic initiation factor 2 and shares sequence identity with the human $\alpha$ subunit. Proc. Natl. Acad. Sci. 86: $2784-2788$.

Cigan, A.M., M. Foiani, E.M. Hannig, and A.G. Hinnebusch. 1991. Complex formation by positive and negative translational regulators of GCN4. Mol. Cell. Biol. 11: 3217-3228.

Dever, T.E., L. Feng, R.C. Wek, A.M. Cigan, T.F. Donahue, and A.G. Hinnebusch. 1992. Phosphorylation of initiation factor $2 \alpha$ by protein kinase $G C N 2$ mediates gene-specific translational control of GCN4 in yeast. Cell 68: 585-596.

Dieckmann, C.L. and A. Tzagoloff. 1985. Assembly of the mitochondrial membrane system. I. Biol. Chem. 260: 15131520.

Donahue, T.F. and A.M. Cigan. 1988. Genetic selection for mutations that reduce or abolish ribosomal recognition of the HIS4 translational initiator region. Mol. Cell. Biol. 8: 29552963.

Donahue, T.F., P.J. Farabaugh, and G.R. Fink. 1982. The nucleotide sequence of the HIS4 region of yeast. Gene 18: 47-59.
Donahue, T.F., R.S. Daves, G. Lucchini, and G.R. Fink. 1983. A short nucleotide sequence required for regulation of HIS 4 by the general control system of yeast. Cell 32: 89-98.

Donahue, T.F., A.M. Cigan, E.K. Pabich, and B. Castilho-Valavicius. 1988. Mutations at a $\mathrm{Zn}$ (II) finger motif in the yeast eIF- $2 \beta$ gene alter ribosomal start-site selection during the scanning process. Cell 54: 621-632.

Gasior, E., F. Herrera, I. Sadnik, C.S. McLaughlin, and K. Moldave. 1979. The preparation and characterization of a cell free system from Saccharomyces cerevisiae that translates natural messenger ribonucleic acid. J. Biol. Chem. 254: 3965-3969.

Groves, W.E., F.C. Davis, Jr., and B.H. Sells. 1968. Spectrophotometric determination of microgram quantities of protein without nucleic acid interference. Anal. Biochem. 22: 195210.

Gulyas, K.G. and T.F. Donahue. 1992. SSL2, a suppressor of a stem-loop mutation in the HIS4 leader encodes the yeast homolog of human ERCC-3. Cell 69: 1031-1042.

Hershey, J.W.B. 1991. Translational control in mammalian cells. Annu. Rev. Biochem. 60: 717-754.

Hofbauer, R., F. Fessl, B. Hamilton, and H. Ruis. 1982. Preparation of a mRNA-dependent cell-free translation system from whole cells of Saccharomyces cerevisiae. Eur. J. Biochem. 122: 199-203.

Hussain, I. and M.J. Leibowitz. 1986. Translation of homologous and heterologous messenger RNAs in a yeast cell-free system. Gene 46: 13-23.

Jaeger, J.A., D.H. Turner, and M. Zuker. 1989. Predicting optimal and suboptimal secondary structure for RNA. Methods Enzymol. 183: 281-306.

Johnston, M. and R.W. Davis 1984. Sequences that regulate the divergent GAL1-GAL10 promoter in Saccharomyces cerevisiae. Mol. Cell. Biol. 4: 1440-1448.

Klug, A. and D. Rhodes 1987. "Zinc fingers": A novel protein motif for nucleic acid recognition. Trends Biochem. Sci. 12: $464-469$.

Kozak, M. 1991a. Structural features in eukaryotic mRNAs that modulate the initiation of translation. I. Biol. Chem. 266: 19867-19870.

1991b. A short leader sequence impairs the fidelity of initiation by eukaryotic ribosomes. Gene Expression 1: 111115.

Mandel, T. and H. Trachsel. 1989. Yeast, Saccharomyces cerevisiae, cell-free translation: The inhibition of translation by high temperature is reversible. Biochim. Biophys. Acta 1007: 80-83.

Maxam, A.M. and W. Gilbert. 1980. Sequencing end-labelled DNA with base-specific chemical cleavages. Methods Enzymol. 65: 499-560.

Milburn, S.C., J.W.B. Hershey, M.V. Davies, K. Kelleher, and R.J. Kaufman. 1990. Cloning and expression of eukaryotic initiation factor 4B cDNA: Sequence determination identifies a common RNA recognition motif. EMBO I. 9: 27832790 .

Nagawa, F. and G.R. Fink 1985. The relationship between the "TATA" sequence and transcription initiation sites at the HIS4 gene of Saccharomyces cerevisiae. Proc. Natl. Acad. Sci. 82: 8557-8561.

Orr-Weaver, T.L., J.K. Szostak, and R.J. Rothstein. 1983. Genetic applications of yeast transformation with linear and gapped plasmids. Methods Enzymol. 101: 228-245.

Rose, M.D. and J.R. Broach 1991. Cloning genes by complementation in yeast. Methods Enzymol. 194: 195-230.

Rose, M.D., P. Novick, J.H. Thomas, D. Botstein, and G.R. Fink. 1987. A Saccharomyces cerevisiae genomic plasmid bank 
based on a centromere-containing shuttle vector. Gene 60: $237-243$.

Rothstein, R.J. 1983. One-step disruption in yeast. Methods Enzymol. 101: 202-211.

Rozen, F., I. Edery, K. Meerovitch, T.E. Dever, W.C. Merrick, and N. Sonenberg. 1990. Bidirectional RNA helicase activity of eukaryotic translation initiation factors $4 \mathrm{~A}$ and $4 \mathrm{~F}$. Mol. Cell. Biol. 10: 1134-1144.

Sanger, F., S. Nicklen, and A.R. Coulson. 1977. DNA sequencing with chain-terminating inhibitors. Proc. Natl. Acad. Sci. 74: 5463-5467.

Sherman, F., G.R. Fink, and C.W. Lawrence. 1979. Methods in yeast genetics. Cold Spring Harbor Laboratory, Cold Spring Harbor, New York.

Sonenberg, N. 1988. Cap-binding proteins of eukaryotic messenger RNA: Functions in initiation and control of translation. Prog. Nucleic Acid Res. Mol. Biol. 35: 173-207.

Thach, R.E. 1992. Cap recap: The involvement of eIF-4F in regulating gene expression. Cell 68: 177-180.

Weeda, G., R.C.A. van Ham, W. Vermeulen, D. Bootsma, A.J. van der Eb, and J.H.J. Hoeijmakers. 1990. A presumed DNA helicase encoded by ERCC-3 is involved in the human repair disorders xeroderma pigmentosum and Cockayne's syndrome. Cell 62: 777-791.

Winston, F., F. Chumley, and G.R. Fink. 1983. Eviction and transplacement of mutant genes in yeast. Methods Enzymol. 100: 211-228.

Yoon H. and T.F. Donahue 1992. The sui1 suppressor locus in Saccharomyces cerevisiae encodes a translation factor that functions during $t R N A_{i}^{\text {Met }}$ recognition of the start codon. Mol. Cell. Biol. 12: 248-260. 


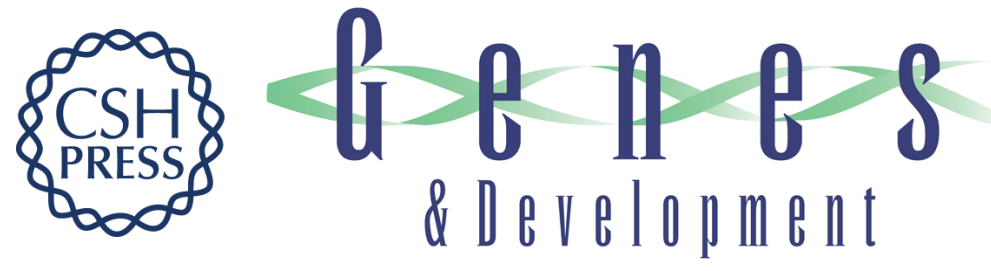

\section{SSL1, a suppressor of a HIS4 5'-UTR stem-loop mutation, is essential for translation initiation and affects UV resistance in yeast.}

H Yoon, S P Miller, E K Pabich, et al.

Genes Dev. 1992, 6:

Access the most recent version at doi:10.1101/gad.6.12b.2463

References This article cites 39 articles, 15 of which can be accessed free at:

http://genesdev.cshlp.org/content/6/12b/2463.full.html\#ref-list-1

License

Email Alerting

Service

Receive free email alerts when new articles cite this article - sign up in the box at the top right corner of the article or click here.

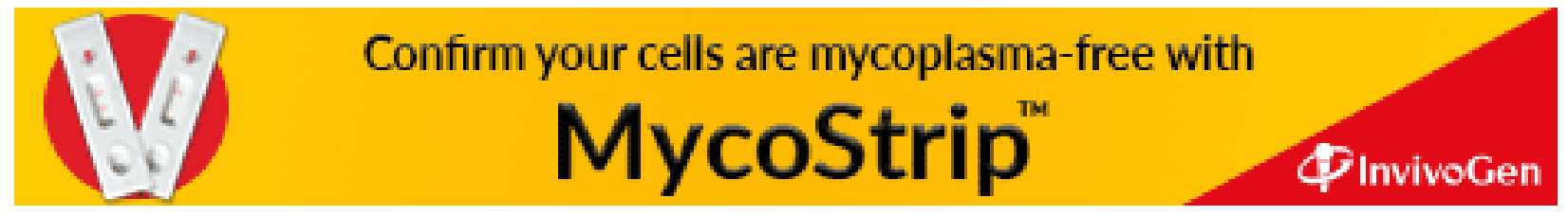

